\title{
Reactions of Gaseous Mercury with Atomic and Molecular Halogens: Kinetics, Product Studies, and Atmospheric Implications
}

\author{
Parisa A. Ariya, Alexei Khalizov, and Alexios Gidas
}

\begin{abstract}
Rapid depletions of atmospheric mercury $\left(\mathrm{Hg}^{0}\right)$ and ozone coinciding with high halogen concentrations have recently been observed in several high-Arctic and sub-Arctic regions. The lack of kinetic data on the halogen-initiated reactions of elemental mercury precluded the drawing of any conclusions on the chemistry of these mercury depletion events. We carried out extensive kinetic and product studies on the reactions of gaseous $\mathrm{Hg}^{0} \mathrm{With}^{\mathrm{T}}$ molecular and atomic halogens $\left(\mathrm{X} / \mathrm{X}_{2}\right.$ where $\left.\mathrm{X}=\mathrm{Cl}, \mathrm{Br}\right)$ at atmospheric pressure $(750 \pm 1$ Torr) and room temperature $(298 \pm 1 \mathrm{~K})$ in air and $\mathrm{N}_{2}$. Kinetics of the reactions with $\mathrm{X} / \mathrm{X}_{2}$ was studied using relative and absolute techniques by cold vapor atomic absorption spectroscopy (CVAAS) and gas chromatography with mass spectroscopic detection (GCMS). The measured rate constants for reactions of $\mathrm{Hg}^{0}$ with $\mathrm{Cl}_{2}, \mathrm{Cl}, \mathrm{Br}_{2}$, and $\mathrm{Br}$ were (2.6 $\pm 0.2) \times 10^{-18},(1.0 \pm 0.2) \times 10^{-11},<(0.9 \pm 0.2) \times 10^{-16}$, and $(3.2 \pm 0.3) \times 10^{-12} \mathrm{~cm}^{3}$ molecule $^{-1} \mathrm{~s}^{-}$ ${ }^{1}$, respectively. The reaction products were analyzed in the gas phase, from the suspended aerosols, and from the wall of the reactor using MS, GC-MS, and inductively coupled plasma mass spectrometry (ICP-MS). The major products identified were $\mathrm{HgCl}_{2}$ and $\mathrm{HgBr}_{2}$ adsorbed on the wall. Suspended aerosols, collected on the micron filters, contributed to less than $0.5 \%$ of the reaction products under our experimental conditions. The importance of halogen reactions of mercury in the formation of particulate matter, which tends to be bioaccumulative, is discussed herein.
\end{abstract}

\section{Introduction}

Mercury is one of the most toxic elements in nature and its dominant form in the atmosphere is $\mathrm{Hg}^{0}$. It has been three

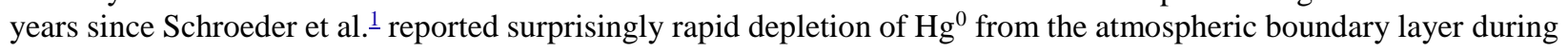
spring in the high-Arctic region at Alert, Canada. Since then, there has been a growing body of observational evidence indicating that $\mathrm{Hg}^{0}$ depletion is widespread throughout the Arctic, $\stackrel{2}{ }$ and sub-Arctic $\underline{3}$ and is associated with enhanced mercury deposition in surface snow and ice. ${ }^{4}$ These episodes of mercury depletion coincide with an ozone hole at the ground driven by sunlight and bromine atoms derived from reactions of atmospheric reactive halogen gases with marine sea salt in surface snow and ice. $\frac{5-8}{-}$ Of particular concern is the deposition of mercury derivatives, as they tend to bioaccumulate. The lack of kinetic studies on the halogen-initiated reactions of gaseous mercury, until this laboratory work, has precluded the drawing of any definite conclusions on the disappearance episodes of mercury. ${ }^{1-3}$ Experimental data on the gaseous reactions of elemental mercury are very limited, in contrast to the vast amount of data on the corresponding reactions of $\mathrm{Hg}^{0}$ in solution that have been extensively studied. Indeed, many gaseous reactions of mercury with atmospherically important oxidants are difficult to investigate experimentally due to the small concentrations of species at atmospheric conditions, low volatility of products, and strong effects of water vapor and surface on kinetics. In the absence of kinetic data, thermodynamic data on reactants and products have been used to calculate reaction enthalpies of $\mathrm{Hg}^{0}$ with a series of oxidants including $\mathrm{O}_{2}, \mathrm{O}\left({ }^{1} \mathrm{D}\right.$ and $\left.{ }^{3} \mathrm{P}\right), \mathrm{HO}_{2}, \mathrm{HO}, \mathrm{CH}_{3} \mathrm{OO}, \mathrm{CH}_{3} \mathrm{O}$, $\mathrm{N}_{2} \mathrm{O}_{5}$, and $\mathrm{NO}_{2} \cdot \frac{9}{}$ - Most of these oxidation species are expected to react via multistep reaction mechanisms involving the formation of various intermediates that may be thermodynamically favorable even if formation of products is 
unfavorable, leading to reasonably fast reaction rates. For instance, the assumption that $\mathrm{HgO}$ and the $\mathrm{H}$ atom were produced in the reaction between mercury and the HO radical has led to a very positive reaction enthalpy, $49.4 \pm 7.9$ kcal mol ${ }^{-1} .9$ Another estimate, using relativistic quantum chemical methods has shown this reaction to produce the $\mathrm{HgOH}$ intermediate instead, with almost zero thermal effect $\left(-1.4 \mathrm{kcal} \mathrm{mol}^{-1}\right)$. $\frac{10}{1} \mathrm{In}$ recent experimental studies, the rate constant for this reaction was determined to be $8.7 \times 10^{-14}$ (at $298 \mathrm{~K}$ ) ${ }^{11}$ and $1.6 \times 10^{-11}$ (at $343 \mathrm{~K}^{12} \mathrm{~cm}^{3} \mathrm{molecules}^{-}$ ${ }^{1} \mathrm{~S}^{-1}$.

Although few studies dealing with the gas-phase reactions between elemental mercury and halogen-containing molecules have been reported, one study $\frac{13}{}$ has shown methyl iodide to be nonreactive toward $\mathrm{Hg}^{0}$ under atmospheric conditions $\left(k<1 \times 10^{-21} \mathrm{~cm}^{3}\right.$ molecule $\left.\mathrm{e}^{-1} \mathrm{~s}^{-1}\right)$. In other studies, $\underline{14-18}$ molecular chlorine was suggested to have a relatively modest reaction rate, $4 \times 10^{-16} \mathrm{~cm}^{3}$ molecules ${ }^{-1} \mathrm{~s}^{-1}$, though the reaction was found to be strongly surface catalyzed, ${ }^{15,16}$ and this value should be considered as an upper limit. Reactions with other molecular halogens have not yet been studied experimentally. As far as the atomic halogens are concerned, to our knowledge, only one study has been reported where the kinetics of the reaction between gaseous mercury and chlorine atoms was followed by monitoring $\mathrm{HgCl}$ using time-resolved absorption spectroscopy in the temperature range $383-443 \mathrm{~K}: \underline{19}$

$$
\begin{gathered}
\mathrm{Hg}^{*}+\mathrm{CFCl}_{3} \rightarrow \mathrm{Hg}+\mathrm{CF}_{3}+\mathrm{Cl} \\
\mathrm{Hg}+\mathrm{Cl} \rightarrow \mathrm{HgCl} \\
\mathrm{HgCl}+\mathrm{HgCl} \rightarrow \mathrm{Hg}_{2} \mathrm{Cl}_{2}
\end{gathered}
$$

The extinction coefficient of $\mathrm{HgCl}$ was evaluated first and the recombination rate constant $k_{3}$ was determined to be $5.0 \times 10^{-10}$ and $3.2 \times 10^{-10} \mathrm{~cm}^{3}$ molecule ${ }^{-1} \mathrm{~s}^{-1}$ in 720 Torr $\mathrm{CF}_{3} \mathrm{Cl}$ and in a mixture of 10 Torr $\mathrm{CF}_{3} \mathrm{Cl}+710 \mathrm{Torr} \mathrm{Ar}$ as a bath gas, respectively. The rate constant $k_{2}$ for the reaction of mercury with chlorine atoms was then derived to be 5.0 $\times 10^{-11} \mathrm{~cm}^{3}$ molecule $\mathrm{s}^{-1}\left(720\right.$ Torr $\left.\mathrm{CF}_{3} \mathrm{Cl}\right)$ and $1.5 \times 10^{-11} \mathrm{~cm}^{3}$ molecule $\mathrm{s}^{-1}\left(10\right.$ Torr $\left.\mathrm{CF}_{3} \mathrm{Cl}+710 \mathrm{Torr} \mathrm{Ar}\right)$ using corresponding values of $k_{3}$. Authors ${ }^{19}$ have mentioned that $k_{2}$ has an uncertainty of a factor of 3 because of the accumulation of experimental errors in evaluating the separate terms. Thus, halogen-initiated reactions of mercury have yet to be evaluated experimentally to assess the role of halogens on the atmospheric transformation of $\mathrm{Hg}^{0}$.

In this paper, we extensively studied the kinetics and products of gas-phase reactions of elemental mercury with atomic and molecular halogens under near tropospheric conditions using cold-vapor atomic absorption spectroscopy (CVAAS), gas chromatography with mass spectroscopic detection (GC-MS), and inductively coupled plasma mass spectrometry (ICP-MS). Complementary chemical kinetics modeling was performed to further understand the reaction mechanism. The implication of the present results to the chemistry of the troposphere is discussed herein.

\section{Experimental Section}

2.1. Kinetics. In the kinetic experiments, reactants and products were monitored using three different detection techniques: cold-vapor atomic absorption spectroscopy (CVAAS), mass spectroscopic detection after separation on a gas chromatograph (GC-MS), and direct sampling from the reaction chamber into the mass spectrometer (direct MS). Kinetic runs were performed at $750 \pm 1$ Torr pressure of bath gas (air or nitrogen) and a temperature of $298 \pm 1$ K. All errors quoted in tables are two standard deviations from least-squares fits unless otherwise stated. However, the errors of the final kinetic data given in the text represent accumulative uncertainties from the least-squares fits $(5-20 \%)$, concentration measurements $(<5 \%)$, and due to adsorption $(<6 \%)$.

CVAAS. The mercury concentration was followed using CVAAS. Light from a Pen-Ray low-pressure mercury lamp (UVP Inc.) was passed through a $0.5 \mathrm{~mm}$ pinhole into a reaction cell equipped with two quartz windows having an optical path of $10 \mathrm{~cm}$. Then, the $253.6 \mathrm{~nm}$ line was isolated with a $0.35 \mathrm{~m}$ McPherson 270 monochromator and detected using a photomultiplier PMT 01-511 (Photon Technology International, Inc.). The detection range for $\mathrm{Hg}^{0}$ was from $10 \mathrm{ppb}$ (part per billion in volume; $1 \mathrm{ppb}=2.46 \times 10^{10}$ molecule $\mathrm{cm}^{-3}$ ) to $2 \mathrm{ppm}$ (part per million in volume; $1 \mathrm{ppm}=$ $2.46 \times 10^{13}$ molecule $\left.\mathrm{cm}^{-3}\right)$.

GC-MS. Concentrations of mercury and a reference molecule were monitored by MS detection (quadrupole MSD HP 5973) after separation on a gas chromatograph (HP 6890) equipped with a $0.25 \mathrm{~mm}$ i.d. $\times 30 \mathrm{~m}$ cross-linked phenyl-methyl-siloxane column (HP 5-MS). The column was operated at a constant flow $\left(1.5 \mathrm{~mL} \mathrm{~min}^{-1}\right) \mathrm{of} \mathrm{helium}^{\circ}$ and was kept isothermal at $0-20{ }^{\circ} \mathrm{C}$ for $2 \mathrm{~min}$. The oven temperature was increased by $25-35^{\circ} \mathrm{C} \min ^{-1}$ up to $170{ }^{\circ} \mathrm{C}$. At the beginning of each kinetic run, the first analysis was performed using the scanning (Scan) mode of the MSD, then the kinetics was followed using the single ion monitoring (SIM) mode. In the latter case, mercury ions with $\mathrm{m} / \mathrm{z}, 199,200,201$, and 202 were monitored. The observed isotopic ratios for these ions corresponded well to the 
expected, 56:78:44:100. The retention time of the mercury peak was from 1.5 to 1.9 min depending on the temperature of the column. The detection limit for $\mathrm{Hg}^{0}$ was $10 \mathrm{ppb}$.

Direct MS sampling. Our setup was analogous to that described by Khamaganov et al. ${ }^{20}$ The reaction chamber was continuously sampled through a $100 \mu \mathrm{m}$ i.d. deactivated fused silica capillary (Supelco) approximately $130 \mathrm{~cm}$ long into the ion source of a mass spectrometer (quadrupole MSD HP 5973). The capillary entered the reaction chamber through a septum port. The flow rate through the column was approximately $0.3 \mathrm{~mL} \mathrm{~min}^{-1}$ as calculated using the geometrical parameters of the column and the 1 bar pressure difference between the reaction chamber and the MSD manifold. With this technique the reactions were always studied using nitrogen as a diluent gas to avoid damage to the ion source. The MSD was operated in SIM mode to increase sensitivity. Mercury ions with $\mathrm{m} / \mathrm{z} 199,200,201$, and 202 were monitored. The detection limit for $\mathrm{Hg}^{0}$ was $50 \mathrm{ppb}$.

2.1.1. Molecular Halogens. Reactions of mercury with molecular $\mathrm{Cl}_{2}$ and $\mathrm{Br}_{2}$ were studied using the absolute rate technique under pseudo-first-order conditions with respect to $\mathrm{Hg}^{0}(0.5-1.0 \mathrm{ppm}$ of mercury and $10-50 \mathrm{ppm}$ of molecular halogen). The mercury concentration was followed using either CVAAS or direct MS sampling. In the former case, the reaction chamber was a $600 \mathrm{~mL}$ Pyrex cell equipped with two quartz windows. During a typical experiment the cell was filled with 600 Torr of $\mathrm{Hg}$-saturated air or nitrogen and then the pressure was brought to 750 Torr with air or nitrogen containing 50-250 ppm of molecular halogen. In the second case, the reaction was studied in a $3 \mathrm{~L}$ flask. First, chlorine or bromine was introduced into the evacuated flask from a $125 \mathrm{~mL}$ vial containing $50-500$ ppm of molecular halogen, then $\mathrm{Hg}$-saturated nitrogen was added to approximately $400 \mathrm{Torr}$, and finally the pressure in the flask was brought to 750 Torr.

2.1.2. Atomic Halogens. The reactions of mercury with chlorine and bromine atoms were studied using the relative rate technique. For instance, in the case of $\mathrm{Cl}$ atom initiated reactions:

$$
\begin{aligned}
& \mathrm{Cl}+\mathrm{Hg} \stackrel{k_{\mathrm{Hg}}}{\longrightarrow} \text { products } \\
& \mathrm{Cl}+\mathrm{Ref} \stackrel{k_{\mathrm{Ref}}}{\longrightarrow} \text { products }
\end{aligned}
$$

The ratio of the rate constants $k_{\mathrm{Hg}} / k_{\text {Ref }}$ was determined from the following equation:

$$
\ln \left\{[\mathrm{Hg}]_{0} /[\mathrm{Hg}]_{\mathrm{t}}\right\}=k_{\mathrm{Hg}} / k_{\mathrm{Ref}} \ln \left\{[\operatorname{Ref}]_{0} /[\operatorname{Ref}]_{\mathrm{t}}\right\}
$$

where $[\mathrm{Hg}]_{0}$ and $[\mathrm{Ref}]_{0}$ are the initial concentrations, and $[\mathrm{Hg}]_{\mathrm{t}}$ and $[\mathrm{Ref}]_{\mathrm{t}}$ are the concentrations after photolysis. A plot of $\ln \left\{[\mathrm{Hg}]_{0} /[\mathrm{Hg}]_{\mathrm{t}}\right\}$ vs $\ln \left\{[\operatorname{Ref}]_{0} /[\operatorname{Ref}]_{\mathrm{t}}\right\}$ should give a straight line with a zero intercept and a slope of $k_{\mathrm{Hg}} / k_{\mathrm{Ref}}$. Experiments were carried out in 2- and 3-L Pyrex double-wall flasks equipped with a stopper having a double-wall quartz window (2-in. diameter). Water was circulated (Neslab RTE 111) between the walls and the temperature in the flask was held at $298 \pm 1 \mathrm{~K}$. The inside wall of the reaction chamber was coated with halocarbon wax (Supelco) or treated with a dimethyldichlorosilane (DMDCS) reagent (Supelco) to prevent undesirable wall reactions. A vacuum system was used to prepare gaseous mixtures of reactants. Gaseous substrates were introduced directly into evacuated reaction flasks using a 50 or $250 \mu \mathrm{L}$ gastight syringe (Hamilton series 1800 Gastight). Liquid substrates were injected with a 2 or $10 \mu \mathrm{L}$ microsyringe (Hamilton series 700 Microliter) into a $125 \mathrm{~mL}$ reference volume held at 50-100 Torr pressure and connected to the reaction flask and the vacuum manifold through Teflon valves. After complete evaporation and, in some cases, after dilution into the manifold, the reactant vapors were transferred into the reaction flask. Air or nitrogen nearly saturated with mercury vapor at 295-298 K was introduced at approximately 400 Torr, and then the pressure in the flask was brought to 750 Torr.

The kinetic study was performed using repeated irradiation and sampling into the GC-MS with a syringe as well as using continuous irradiation and continuous sampling through a capillary directly into the MSD. Several organic substrates ( $n$-hexane, cyclohexane, $n$-butane, ethane, 1,3-dichloropropane, dichloromethane, and 1-butene) with different reactivities toward chlorine and bromine atoms were used as references in the kinetic experiments. Typical initial concentrations of the reactants were $0.5-1.0 \mathrm{ppm}$ for $\mathrm{Hg}^{0}, 1-12 \mathrm{ppm}$ for the reference, and $10-50 \mathrm{ppm}$ for the halogen atoms source. Cyclohexane and benzene (100-4500 ppm) were used as HO radical scavengers in some experiments.

Halogen atom source and irradiation technique. In preliminary experiments, we found that molecular chlorine and bromine could not be used as halogen atom sources since they react rapidly in the dark with gaseous $\mathrm{Hg}^{0}$. Instead, trichloroacetyl chloride ${ }^{21}$ and dibromomethane ${ }^{22}$ were used to generate atomic chlorine and bromine, respectively. In situ photolysis of the precursor was performed with irradiation produced by a $100 \mathrm{~W} \mathrm{Hg}$ arc lamp (model 6281, Oriel 
Inc). It appears that high-pressure mercury vapor inside the bulb of the lamp acts as a very efficient and narrow filter, removing the $253.6 \mathrm{~nm}$ mercury excitation line from radiated light. $\underline{23}$ This allows a photolysis of an initiator absorbing at $\sim 250 \mathrm{~nm}$ without exciting the mercury atoms in the reaction mixture. Separate experiments were performed to ensure that there was no depletion of $\mathrm{Hg}^{0}$ due to reactions of photoexcited mercury formed upon irradiation by unfiltered light of the arc lamp. Indeed, no decrease of the GC-MS signal of mercury and/or reference compound was observed upon photolysis in a system containing gaseous mercury in air and in nitrogen with or without the reference. However, as was expected, the concentration of mercury decreased rapidly upon irradiation in the presence of a halogen atom source. From the rates of decay of ethane and 1-butene in a typical run, average chlorine and bromine atom concentrations were estimated to be $1.1 \times 10^{7}$ and $4.0 \times 10^{8}$ atom $\mathrm{cm}^{-3}$, respectively.

Repeated irradiation/sampling. Photolysis of the reaction mixture was carried out through a quartz window by repeated 0.5 to $2 \mathrm{~min}$ long steps. Total irradiation times ranged from 10 to $60 \mathrm{~min}$. The decays in concentration of mercury and the reference compound upon photolysis were monitored by injecting gas samples from the reaction flask into the GCMS after each irradiation section using a gastight syringe. The volume of the samples injected was $200 \mu \mathrm{L}$.

Continuous irradiation/sampling. Photolysis of the reaction mixture was carried out continuously and the flask was continuously sampled through a capillary into the ion source of the MSD. Since the volume by surface ratio of the capillary was very small, special precautions were taken to avoid exposure of the capillary to irradiation in order to impede photochemistry occurring inside it. The light column coming in through the quartz window did not irradiate the entire contents of the flask; therefore, a Teflon stirrer was designed to ensure fast thorough mixing. Using the velocity of the gas passing through and the length of the capillary, the residence time in the capillary was calculated to be about $1.5 \mathrm{~s}$.

2.2. Product Studies. Reaction products were generally preconcentrated in a trap cooled by liquid nitrogen or dissolved in small volume of solvent before analysis. For all products $\left(\mathrm{Hg}^{0}, \mathrm{HgCl}_{2}, \mathrm{HgBr}_{2}, n\right.$ - $\left.\mathrm{Bu}_{2} \mathrm{Hg}\right)$ the measured isotopic ratios of ions in mass-spectra within $0.5-2 \%$ corresponded to the expected ratios.

Direct probe. Volatile products were collected by passing a slow flow of gas from a reaction chamber through a 1.1 mm i.d. $\times 10 \mathrm{~cm}$ length Pyrex tube (Corning), the central part of which was maintained at liquid nitrogen temperature. Condensed products were evaporated from the tube into an ion source of a Kratos MS25RFA mass spectrometer at stepwise-elevated temperature using a direct probe.

Derivatization. This method is based on the quantitative transformation of $\mathrm{HgX}_{2}(\mathrm{X}=\mathrm{Cl}, \mathrm{Br})$ to the significantly more volatile organomercury compound $n-\mathrm{Bu}_{2} \mathrm{Hg}$ :

$$
\mathrm{HgX}_{2}+2 n-\mathrm{BuMgCl} \rightarrow n-\mathrm{Bu}_{2} \mathrm{Hg}+2 \mathrm{MgClX}
$$

Samples were prepared by washing the traps or reaction flask walls with toluene. Since the solubility of mercury products in toluene is moderate $\left(\sim 5 \mathrm{~g} \mathrm{~L}^{-1}\right)$, ultrasound was used to accelerate dissolution. Derivatization was performed using a previously reported procedure. $\frac{24,25}{\mathrm{~A}} 1-\mathrm{mL}$ sample in toluene was placed in a $10 \mathrm{~mL}$ centrifuge test tube. It was derivatized with $0.4 \mathrm{~mL}$ of $2 \mathrm{M} n$-butylmagnesiumchloride in tetrahydrofuran for $5 \mathrm{~min}$ in an ice-water bath with occasional shaking. Subsequently, $0.4 \mathrm{~mL}$ of $0.6 \mathrm{M}$ hydrochloric acid was added to quench the excess derivatization agent, the mixture was centrifuged, and the organic phase was removed for analysis. It should be noted that $\mathrm{Hg}_{2} \mathrm{X}_{2}$ is not derivatized under these conditions. ${ }^{25}$

ICP-MS. Samples were prepared by treating the reaction flask walls and Teflon filters with a mixture of $20 \mathrm{~mL} 40 \%$ $\mathrm{HNO}_{3}$ and $0.5 \mathrm{~mL} 30 \% \mathrm{H}_{2} \mathrm{O}_{2}$. The samples were diluted to $100 \mathrm{~mL}$, heated to $350 \mathrm{~K}$ during an hour to decompose $\mathrm{H}_{2} \mathrm{O}_{2}$, and analyzed by ICP-MS.

2.3. Materials. Chemicals: mercury ( $99.9995 \%$ purity), chlorine $(99.5+\%)$, bromine $(99.5+\%)$, mercury (II) chloride (99.999\%), mercury (II) bromide (99.998\%), dibromomethane (99\%), trichloroacetyl chloride (99\%), benzene $(99+\%)$, ethane $(99+\%), n$-butane $(98+\%), n$-nonane $(99 \%), 1,3$-dichloropropane (99\%), and $n$-butylmagnesium chloride (2M solution in tetrahydrofuran) were purchased from Aldrich. Cyclohexane (99.7\%), toluene (99.9\%), dichloromethane (99.9\%), hydrogen peroxide (30\%), hydrochloric acid (TraceMetal grade), and nitric acid (TraceMetal grade) were supplied by Fisher. $n$-Hexane $(99.5 \%)$ was purchased from Sigma. All the reagents were used as received. The UHP nitrogen and the Ultra Zero air were purchased from Megs (Matheson).

2.4. Computational Studies. The Gaussian 98 package was used for quantum chemical calculations. $\frac{26}{K}$ Kinetic modeling of the reaction systems was performed using the Acuchem program. $\underline{27}$

\section{Results and Discussions}

3.1. Wall Effects. To ensure spatial and temperature homogeneity, the reaction chambers used in our experiment were 2- and 3-L Pyrex flasks. Therefore, special attention was drawn to a loss of reactants on the walls that might bias 
kinetic data and to possible photochemical reactions catalyzed by wall surfaces. Blank experiments revealed a decrease of gas-phase concentrations immediately after addition of a mixture of reactants to a flask that was thoroughly evacuated before the experiment to a residual pressure of 0.05 mTorr. The decrease obeyed an exponential dependence reaching a plateau, the effect being most pronounced in a Pyrex flask with nontreated walls. Seemingly, when a fresh surface of the flask was exposed to a mixture of reactants, adsorption processes from the gas phase to the wall occurred. The rate of adsorption was best described by fitting the experimental data to eq 8 rather than to a simple exponential:

$$
y(t)=y_{0}+a \times \exp \left(-k_{\mathrm{ads}} \times t\right)
$$

where $y(t)$ is the gas-phase concentration of a species at time $t ; y_{0}$ is a parameter corresponding to gas-phase concentration of a species at infinite time; $a$ is a parameter corresponding to maximum adsorption capacity of the wall expressed as gas-phase concentration, and $k_{\text {ads }}$ is the effective rate constant of adsorption. Using this equation, $k_{\text {ads }}$ and maximum relative loss of reactants at infinite time due to adsorption, $L_{\mathrm{m}}=a /\left(a+y_{0}\right)$, were calculated for mercury and several references. Table 1 shows that noticeable amounts of mercury and 1,3-dichloropropane (1,3-DCP) were adsorbed in a nontreated Pyrex flask. Applying the DMDCS coating led to more than a 2-fold decrease of the adsorption rate of mercury and 1,3-DCP, but had virtually no effect on $L_{\mathrm{m}}$. At the same time, in a flask coated with halocarbon wax, both $k_{\mathrm{ads}}$ and $L_{\mathrm{m}}$ decreased significantly, so halocarbon wax coating was used in all kinetic experiments. In the most severe case, with 1,3-DCP used as a reference, the decrease in concentration was about $9 \%$ over the 10-minute period immediately after the addition of reactants to the flask, and did not exceed $4 \%$ over the several hours that followed (Table 1). Similar trends in $k_{\text {ads }}$ and $L_{\mathrm{m}}$ vs type of coating were observed for other references, but the adsorption was much weaker for less polar and/or lower molecular weight compounds such as ethane, 1-butene, $n$-butane, and $n$-hexane.

\section{TABLE 1: Wall Loss from the Gas Phase for Mercury $\left([\mathrm{Hg}]_{0}=0.5 \mathrm{Ppm}\right)$ and Reference $\left([1,3-\mathrm{DCP}]_{0}=5.7 \mathrm{ppm}\right)$ in a 3-L Flask with Different Types of Wall Coating in the Presence of Trichloroacetyl Chloride $(48 \mathrm{ppm})$ and Benzene (835 ppm) at $298 \mathrm{~K}^{a}$}

\begin{tabular}{lccc}
\hline \multicolumn{1}{c}{ wall } & $k_{\text {ads }}, \min ^{-1}$ & $L_{\mathrm{m}} \%$ & $\Delta y(t=10 \mathrm{~min}) \%$ \\
\hline Hg & & & \\
Pyrex & 0.130 & 30.6 & 22.3 \\
DMDCS & 0.058 & 29.1 & 12.8 \\
HW & 0.090 & 6.6 & 3.9 \\
1,3-DCP & & & \\
Pyrex & 0.200 & 26.1 & 22.5 \\
DMDCS & 0.095 & 23.5 & 14.4 \\
HW & 0.120 & 12.6 & 8.8
\end{tabular}

${ }^{a} k_{\text {ads }}$ is effective rate constant of adsorption; $L_{\mathrm{m}}=a /\left(a+y_{0}\right)$ is adsorption wall capacity; $\Delta y(t=10 \mathrm{~min})$ is loss from gas phase to the wall during the 10 min period after mixing the reagents.

To minimize the effect of adsorption on the reaction kinetics, the mixture of reactants was always given enough time to equilibrate with the walls before irradiation was started or molecular halogens were added. For instance, in kinetic experiments with GC-MS monitoring, where a typical run was as long as $3 \mathrm{~h}$ due to the GC-MS analysis step, the reaction mixture was usually kept for at least $2 \mathrm{~h}$ for equilibration before the irradiation began. At the same time, kinetic experiments were significantly shorter when continuous MS sampling was used. Thus, the irradiation was started 10 to 15 min after addition of reactants, when their decay caused by adsorption was much slower than their reaction with halogen atoms. Usually, over the 5 to 20 min remaining of the kinetic run, the change of reactant concentration due to adsorption did not exceed $2 \%$ of their initial concentration. This led to an uncertainty in the calculated relative rate constant, which varied from $4 \%\left(k_{\mathrm{Hg}} / k_{\mathrm{Ref}} \sim 1\right)$ to $60 \%\left(k_{\mathrm{Hg}} / k_{\mathrm{Ref}} \sim 10\right)$.

To evaluate if adsorbed reactants could desorb back to the gas phase when their gaseous concentrations decreased due to reaction with atomic halogens, we performed experiments at high initiation rates when the adsorption/desorption process $(\tau=10 \mathrm{~min})$ was significantly slower than chemical transformation $(\tau=2 \mathrm{~min})$. No increase in concentration 
of reactants was detected when the irradiation was stopped at any degree of conversion, providing evidence that no observable desorption occurred.

The contribution of surface reactions induced by light to observed kinetics was also found to be negligible. Indeed, since the reaction mixture was photolyzed through a quartz window, only a small spherical cap opposite the window ( $9 \%$ of the total wall surface) was irradiated by a column of light. Even at full extent of adsorption less than $1 \%$ of the reactants loaded was subjected to photolysis at the wall surface.

3.2. Reaction of $\mathbf{C l}_{2}$ and $\mathrm{Br}_{2}$ with $\mathbf{H g}^{\mathbf{0}}$. In previous studies, ${ }^{15,16}$ it has been noted that the reaction of mercury with molecular chlorine is strongly catalyzed by surfaces. Therefore, to minimize this effect, the reaction cell was coated with halocarbon wax for kinetic experiments. Indeed, the kinetic system appeared to be very sensitive to the nature of the wall: removing the halocarbon wax coating dramatically increased the rate of mercury depletion (Figure 1, Table 2). This explains the lack of mercury in the samples taken from the reaction cell and analyzed using GC-MS when we attempted to use a gastight syringe. The surface-catalyzed reaction occurred in the syringe and/or in the GC inlet, leading to extremely fast mercury consumption in the sample.

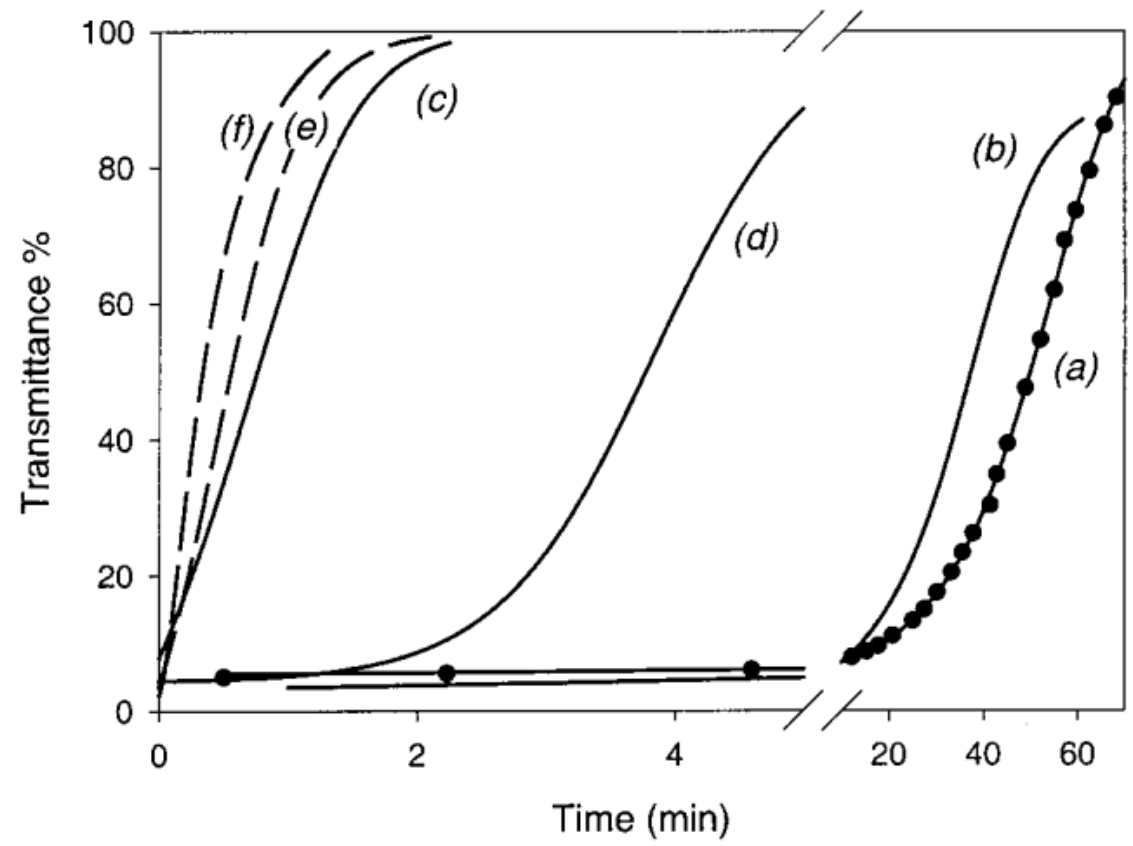

Figure 1. Time evolution of optical transmittance at $253.7 \mathrm{~nm}$ in the cell containing $0.5-1.0 \mathrm{ppm}$ of $\mathrm{Hg}^{0}$ and $(\mathrm{a}-\mathrm{d}) 10 \mathrm{ppm}$ of $\mathrm{Cl}_{2}$ or $(\mathrm{e}-\mathrm{f})$ $20 \mathrm{ppm}$ of $\mathrm{Br}_{2}$ in $\mathrm{N}_{2}$ at $298 \mathrm{~K}$. (a) wall treated with halocarbon wax, noncontinuous probing light; (b) wall treated with halocarbon wax, continuous probing; (c) nontreated Pyrex wall, continuous probing; (d) in the presence of $\mathrm{Hg}^{0}+\mathrm{Br}_{2}$ reaction products on the wall treated with halocarbon wax, continuous probing; (e) wall treated with halocarbon wax; (f) nontreated Pyrex wall. 
https://pubs.acs.org/doi/abs/10.1021/jp020719o

TABLE 2: Rate Constants for the Reaction of Mercury with Molecular Chlorine and Bromine $\left(\mathbf{X}_{2}\right)$ in $\mathbf{N}_{2}$ at $298 \mathrm{~K}^{a}$

\begin{tabular}{|c|c|c|c|c|c|c|}
\hline \multirow[b]{2}{*}{$V_{\text {cell, }} \mathrm{L}$} & \multirow[b]{2}{*}[\mathrm{X}_{2}]{, $\mathrm{ppm}$} & \multirow[b]{2}{*}{ method } & \multicolumn{2}{|c|}{$k_{\mathrm{i}}$} & \multicolumn{2}{|c|}{$k_{\mathrm{ii}}$} \\
\hline & & & $10^{-3} \mathrm{~s}^{-1}$ & $\begin{array}{c}10^{-18} \mathrm{~cm}^{3} \\
\text { molecule }{ }^{-1} \mathrm{~s}^{-1}\end{array}$ & $10^{-3} \mathrm{~s}^{-1}$ & $\begin{array}{c}10^{-18} \mathrm{~cm}^{3} \\
\text { molecule }{ }^{-1} \mathrm{~s}^{-1}\end{array}$ \\
\hline \multicolumn{7}{|c|}{ Chlorine } \\
\hline 0.65 & 10 & $\mathrm{CVAAS}^{b, c}$ & $0.24 \pm 0.01$ & $0.97 \pm 0.04$ & $0.67 \pm 0.03$ & $2.47 \pm 0.11$ \\
\hline 0.65 & 10 & $\mathrm{CVAAS}^{b, d}$ & $0.44 \pm 0.02$ & $1.80 \pm 0.08$ & $1.21 \pm 0.02$ & $4.91 \pm 0.08$ \\
\hline 0.65 & 10 & CVAAS $^{d, e}$ & $37.5 \pm 1.0$ & $152.2 \pm 4.1$ & & \\
\hline 0.65 & 10 & CVAAS $^{b, d, f}$ & $2.8 \pm 0.5$ & $11.2 \pm 2.0$ & & \\
\hline 3.0 & 10 & $\mathrm{MS}^{b}$ & $0.65 \pm 0.01$ & $2.66 \pm 0.04$ & $1.03 \pm 0.03$ & $4.19 \pm 0.12$ \\
\hline 3.0 & 30 & $\mathrm{MS}^{b}$ & $1.93 \pm 0.04$ & $2.62 \pm 0.05$ & $3.17 \pm 0.31$ & $4.29 \pm 0.42$ \\
\hline 3.0 & 50 & $\mathrm{MS}^{b}$ & $3.24 \pm 0.10$ & $2.63 \pm 0.08$ & $5.59 \pm 0.35$ & $4.55 \pm 0.28$ \\
\hline \multicolumn{7}{|c|}{ Bromine } \\
\hline 0.65 & 20 & CVAAS $^{b}$ & $45.9 \pm 0.3$ & $93.4 \pm 0.6$ & & \\
\hline 0.65 & 20 & CVAAS $^{e}$ & $57.2 \pm 1.4$ & $116.2 \pm 2.8$ & & \\
\hline
\end{tabular}

Since there was a possibility of molecular chlorine photolysis by the probe light in CVAAS experiments, a comparison of continuous and interrupted monitoring was performed; in the latter case a light shutter was used to close the probe beam. To measure the optical transmittance during the course of the reaction, the light shutter was opened for 2-3 s with 2 min intervals. Figure 1 shows that the effect of photolysis was small but not negligible.

The reaction rate appeared to accelerate at higher conversions of mercury, leading to two kinetic regimes that we attributed to (i) gas-phase reaction and (ii) surface-catalyzed reactions in addition to the gas phase. This effect has been confirmed in all sets of experiments using CVAAS and direct MS detection techniques. As depicted in Figure 2, when the concentration of molecular chlorine was increased, the rate of consumption of elemental mercury increased in a way that was consistent with the second-order nature of the reaction. The rate constant calculated from this concentration dependence for the first part of the kinetic curve was $(2.62 \pm 0.08) \times 10^{-18} \mathrm{~cm}^{3}$ molecule $\mathrm{e}^{-1} \mathrm{~s}^{-1}$. As the reaction proceeded, the reaction rate accelerated, leading to regime (ii). The rate constant calculated for the second part of the kinetic curve was $(4.63 \pm 0.28) \times 10^{-18} \mathrm{~cm}^{3}$ molecule ${ }^{-1} \mathrm{~s}^{-1}$. In all our experiments, the beginning of the second part of the kinetic curve corresponded to approximately the same degree of converted mercury ( $60 \%$ in $3-\mathrm{L}$ and $20-30 \%$ in $0.6-\mathrm{L}$ flasks, respectively). This suggests that a certain amount of oxidized mercury, which we identified to be predominantly $\mathrm{HgCl}_{2}$, must be formed before the catalytic acceleration can start. $\mathrm{Since}_{\mathrm{HgCl}}$ is significantly less volatile than elemental mercury, its vapor saturates at approximately $10 \%$ conversion of $\mathrm{Hg}^{0}$, leading to deposition of $\mathrm{HgCl}_{2}$ on the walls of the reaction cell. The observation of the catalyzed reactions occurring only at a higher conversion supports the hypothesis that first the reaction chamber walls need to be covered by products before a substantial amount of these types of heterogeneous reactions can occur. We also observed a strong acceleration effect when the reaction between mercury and molecular chlorine was studied in a cell covered with $\mathrm{Hg}^{0}+\mathrm{Br}_{2}$ reaction products (Figure 1). A similar surface effect on the $\mathrm{Hg}+\mathrm{Cl}_{2}$ reaction has already been observed. The reaction has been found to proceed through a surface catalysis stoichiometrically producing $\left(\mathrm{HgCl}_{2}\right)_{n}$ on the walls: ${ }^{15}$

$$
n \mathrm{Hg}+n \mathrm{Cl}_{2} \rightarrow\left(\mathrm{HgCl}_{2}\right)_{n}
$$

In another study, ${ }^{16}$ the overall reaction rate has been noticed to increase after prolonged exposure of the cell to air mixtures containing mercury vapor and molecular chlorine. 


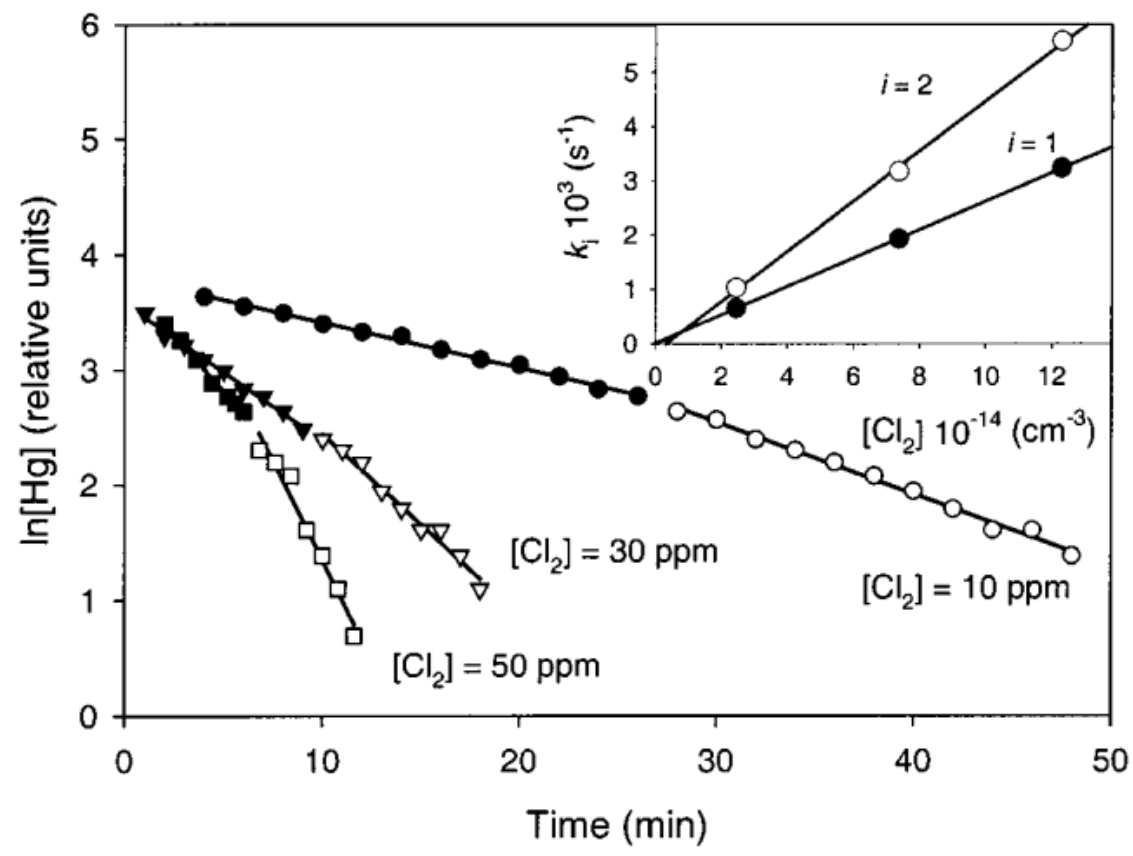

Figure 2. Semilogarithmic plots of change in the MS signal of mercury over time at different initial concentrations of molecular chlorine $\left(1 \mathrm{ppm}=2.46 \times 10^{13}\right.$ molecule $\left.\mathrm{cm}^{-3}\right)$. Reaction was carried out in a 3 -L flask coated with halocarbon wax at $298 \mathrm{~K}$. Inset shows dependence of the pseudo-first-order rate constant for the first $(i=1)$ and second $(i=2)$ parts of the kinetic curve on the initial concentration of molecular chlorine.

The linearity of the kinetic data shown in Figure 2 corresponding to the first regime suggests that at low conversion of $\mathrm{Hg}^{0}$, the extent of secondary reactions arising from surface catalysis, or any other potential heterogeneous process, is insignificant. The rate constants obtained for the first regime using different methods $\left(1.0^{-} 2.6\right) \times 10^{-}$ ${ }^{18} \mathrm{~cm}^{3}$ molecule $\mathrm{e}^{-1} \mathrm{~s}^{-1}$ are significantly lower than the previously estimated value, $4 \times 10^{-16} \mathrm{~cm}^{3}$ molecule ${ }^{-1} \mathrm{~s}^{-1} .{ }^{17,18}$ One can see that the latter value is actually close to what we measured for the uncoated Pyrex surface, $(1.52 \pm 0.04) \times 10^{-}$ ${ }^{16} \mathrm{~cm}^{3}$ molecule ${ }^{-1} \mathrm{~s}^{-1}$ (Table 2).

Molecular bromine was found to react with mercury significantly faster than $\mathrm{Cl}_{2}$. It follows from Figure 1 and Table 2 that in a cell treated with halocarbon wax the reaction rate was similar to the rate of reaction with $\mathrm{Cl}_{2}$ in a nontreated cell. It should be noted that all our attempts to study the reaction $\mathrm{Hg}+\mathrm{Br}_{2}$ using the direct MS technique failed. The mercury signal disappeared in a few seconds upon mixing the reagents and bringing the flask to atmospheric pressure. Only trace amounts of mercury were observed after transfer of reaction mixture from the flask into MS through a capillary. Seemingly, due to very strong wall effects, the reaction was fully completed in the capillary before the mixture reached the ion source of the MS detector. We may conclude that, contrary to the reaction of $\mathrm{Hg}^{0}$ with molecular chlorine, the value of the rate constant obtained for molecular bromine, $(0.9 \pm 0.2) \times 10^{-16} \mathrm{~cm}^{3}$ molecule ${ }^{1} \mathrm{~s}^{-1}$, is only an upper estimate.

3.3. Reaction of $\mathbf{C l}$ and $\mathbf{B r}$ with $\mathbf{H g}^{\mathbf{0}}$. 3.3.1. Kinetics. We used the relative rate technique in the kinetic studies of $\mathbf{C l}$ and $\mathrm{Br}$ atom initiated reactions of $\mathrm{Hg}^{0}$. Since the absolute rate constants for these reactions are unknown and their evaluation in a relative rate study is a function of the absolute rate constant of the reference, five different reference molecules were used to obtain a better estimate (Table 3). 
TABLE 3: Literature Values of Rate Constants $\left(\mathrm{cm}^{3}\right.$ molecule $\left.{ }^{-1} \mathbf{s}^{-1}\right)$ for the Reaction of References Employed with Atomic Halogens $(\mathrm{X}=\mathrm{Cl}$ and $\mathrm{Br})$ and the Hydroxyl Radical at $298 \mathrm{~K}$

\begin{tabular}{llcc}
\hline \multicolumn{1}{c}{ substrate } & \multicolumn{1}{c}{$k_{x} \times 10^{-11}$} & $k_{\mathrm{HO}} \times 10^{-13}$ & $k_{x} / k_{\mathrm{HO}}$ \\
\hline ethane & $\mathrm{X}=\mathrm{Cl}, 5.7^{29}$ & $2.6^{42}$ & 217 \\
1,3-dichloropropane & $\mathrm{X}=\mathrm{Cl}, 11^{43}$ & $7.8^{43}$ & 14 \\
dichloromethane & $\mathrm{X}=\mathrm{Cl}, 0.034^{29}$ & $1.1^{44}$ & 3 \\
$n$-hexane & $\mathrm{X}=\mathrm{Cl}, 31^{45}$ & $54^{42}$ & 56 \\
$n$-butane & $\mathrm{X}=\mathrm{Cl}, 22^{46}$ & $24^{42}$ & 92 \\
1-butene & $\mathrm{X}=\mathrm{Br}, 0.34^{37}$ & $314^{47}$ & 0.1 \\
Hg & $\mathrm{X}=\mathrm{Cl}, 1.5^{19}$ & $0.87^{11}\left(160^{b 12}\right)$ & $188(0.9)$ \\
& $\mathrm{X}=\mathrm{Cl}, 1.0^{a}$ & & $125(0.6)$ \\
& $\mathrm{X}=\mathrm{Br}, 0.3^{a}$ & & $35(0.2)$
\end{tabular}

${ }^{a}$ Value from the present work. ${ }^{b}$ At $343 \mathrm{~K}$.

Reaction $\mathrm{Hg}^{0}+\mathrm{Cl}$. Table 4 presents relative and absolute rate constants for the reaction of mercury with chlorine atoms obtained using repeated irradiation/syringe and direct MS sampling techniques with different reference compounds. Good linearity of relative rate plots was observed for ethane, $n$-butane, and $n$-hexane, though a slight curvature was noted in the very beginning of the plot at high concentration of the reference in air. Generally, the slope depended on the concentration of the reference, increasing at higher concentrations. The effect was pronounced to a greater extent in air, rather than in nitrogen, diluent (see Figure 3), indicating secondary reactions caused by the presence of molecular oxygen. As Table 4 displays, small hydrocarbons such as ethane, which produce fewer oxidation products, led to a lesser extent of secondary reactions than did larger molecules such as $n$-hexane. Values as high as $(9.8 \pm 1.0) \times 10^{-10} \mathrm{~cm}^{3}$ molecule $\mathrm{e}^{-1} \mathrm{~s}^{-1}$ were obtained in air using high concentrations of relatively large hydrocarbons such as $n$-hexane and $n$-butane. Seemingly, it was the HO radical formed upon oxidation of the reference molecule that caused these secondary reactions. The mechanism for formation of $\mathrm{HO}$ has been suggested to involve reaction of $\mathrm{Cl}$ atoms with hydroperoxides. ${ }^{28}$ For instance, the $\mathrm{Cl}$ atom initiated oxidation of $\mathrm{C}_{2} \mathrm{H}_{6}$ in air produces $\mathrm{C}_{2} \mathrm{H}_{5} \mathrm{OOH}$, which can then react with $\mathrm{Cl}$ atoms to give $\mathrm{HO}$ radicals:

$$
\begin{gathered}
\mathrm{Cl}+\mathrm{C}_{2} \mathrm{H}_{5} \mathrm{OOH} \rightarrow \mathrm{CH}_{3} \mathrm{CHOOH}+\mathrm{HCl} \\
\mathrm{CH}_{3} \mathrm{CHOOH} \rightarrow \mathrm{CH}_{3} \mathrm{CHO}+\mathrm{HO}
\end{gathered}
$$

$\mathrm{HO}$ may be produced by the reaction of $\mathrm{Cl}$ atoms with $\mathrm{HO}_{2}: \underline{29}$

$$
\mathrm{Cl}+\mathrm{HO}_{2} \rightarrow \mathrm{HO}+\mathrm{ClO}
$$

Photolysis of hydroperoxides by short wave UV irradiation $(\lambda>250 \mathrm{~nm})$ employed in our study might also have

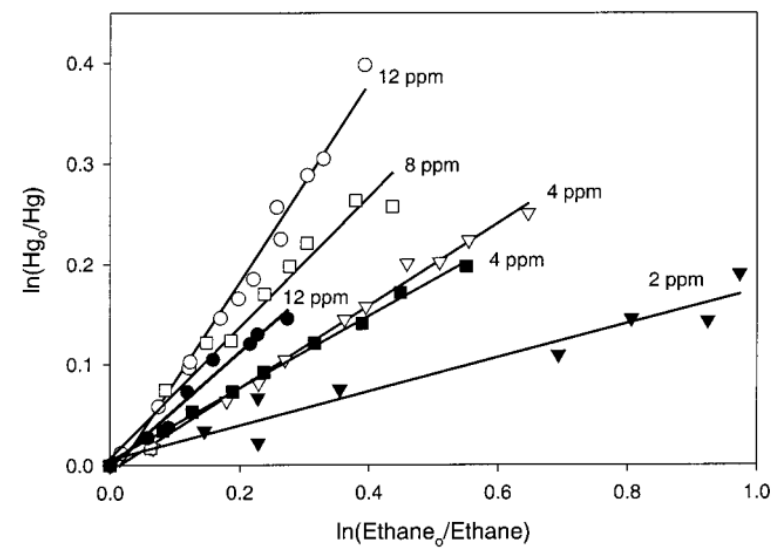

Figure 3. Typical relative rate data for reaction $\mathrm{Hg}^{0}+\mathrm{Cl}$ obtained using ethane as a reference. Kinetic runs were performed at $298 \mathrm{~K}$ using syringe sampling in air (open symbols) and in nitrogen (filled enhanced $\mathrm{HO}$ radical formation. symbols) with different initial concentrations of the reference, ethane. 
https://pubs.acs.org/doi/abs/10.1021/jp020719o

TABLE 4: Rate Constants for the Reaction of Mercury
with Chlorine Atoms Obtained Using Different References
at $298 \mathrm{~K}^{a}$

\begin{tabular}{|c|c|c|c|c|}
\hline$V_{\mathrm{fl}}, \mathrm{L}$ & $\begin{array}{c}\text { bath } \\
\text { gas }\end{array}$ & $\begin{array}{l}\text { reference, } \\
\text { ppm }\end{array}$ & $k_{\mathrm{Hg}} / k_{\mathrm{Ref}}$ & $\begin{array}{c}k_{\mathrm{Hg}+\mathrm{Cl}} \times 10^{11} \mathrm{~cm}^{3} \\
\text { molecule }{ }^{-1} \mathrm{~s}^{-1}\end{array}$ \\
\hline \multicolumn{5}{|c|}{ Syringe Sampling } \\
\hline 2 & air & $n$-hexane, 6.0 & $0.42 \pm 0.02$ & $12.8 \pm 0.6$ \\
\hline \multirow[t]{2}{*}{2} & air & $n$-hexane, 10.0 & $3.07 \pm 0.41$ & $93.5 \pm 12.5$ \\
\hline & & $n$-butane, 5.0 & $4.55 \pm 0.48$ & $97.7 \pm 10.3$ \\
\hline 2 & air & $\mathrm{CH}_{2} \mathrm{Cl}_{2}, 8.0$ & $10.8 \pm 5.9$ & $0.36 \pm 0.20$ \\
\hline 3 & air & ethane, 4.0 & $0.41 \pm 0.02$ & $2.36 \pm 0.12$ \\
\hline 3 & air & ethane, 4.0 & $0.40 \pm 0.02$ & $2.30 \pm 0.12$ \\
\hline 3 & air & ethane, 8.0 & $0.70 \pm 0.04$ & $4.01 \pm 0.23$ \\
\hline 3 & air & ethane, 12.0 & $0.86 \pm 0.02$ & $4.89 \pm 0.11$ \\
\hline 2 & $\mathrm{~N}_{2}$ & $n$-hexane, 6.0 & $0.20 \pm 0.02$ & $6.04 \pm 0.60$ \\
\hline 2 & $\mathrm{~N}_{2}$ & $\mathrm{CH}_{2} \mathrm{Cl}_{2}, 8.0$ & $6.58 \pm 0.40$ & $0.22 \pm 0.01$ \\
\hline 2 & $\mathrm{~N}_{2}$ & ethane, 4.0 & $0.35 \pm 0.04$ & $1.99 \pm 0.23$ \\
\hline 3 & $\mathrm{~N}_{2}$ & ethane, 12.0 & $0.58 \pm 0.08$ & $3.32 \pm 0.46$ \\
\hline 3 & $\mathrm{~N}_{2}$ & ethane, 4.0 & $0.36 \pm 0.02$ & $2.05 \pm 0.11$ \\
\hline 3 & $\mathrm{~N}_{2}$ & ethane, 2.0 & $0.18 \pm 0.03$ & $1.03 \pm 0.17$ \\
\hline \multicolumn{5}{|c|}{ Direct MS Sampling } \\
\hline 3 & $\mathrm{~N}_{2}$ & $1,3-\mathrm{DCP}, 0.7^{b}$ & $0.97 \pm 0.22$ & $1.06 \pm 0.24$ \\
\hline 3 & $\mathrm{~N}_{2}$ & 1,3 -DCP, $1.4^{b}$ & $0.94 \pm 0.08$ & $1.03 \pm 0.09$ \\
\hline 3 & $\mathrm{~N}_{2}$ & $1,3-\mathrm{DCP}, 2.1^{b}$ & $0.92 \pm 0.09$ & $1.01 \pm 0.10$ \\
\hline 3 & $\mathrm{~N}_{2}$ & 1,3 -DCP, $2.8^{b}$ & $0.91 \pm 0.09$ & $1.00 \pm 0.10$ \\
\hline 3 & $\mathrm{~N}_{2}$ & $1,3-\mathrm{DCP}, 3.5^{b}$ & $1.01 \pm 0.07$ & $1.11 \pm 0.08$ \\
\hline 3 & $\mathrm{~N}_{2}$ & $1,3-\mathrm{DCP}, 14.0^{b}$ & $1.10 \pm 0.05$ & $1.21 \pm 0.06$ \\
\hline 3 & $\mathrm{~N}_{2}$ & $\mathrm{CH}_{2} \mathrm{Cl}_{2}, 8.3$ & $5.24 \pm 0.25$ & $0.18 \pm 0.01$ \\
\hline 3 & $\mathrm{~N}_{2}$ & $\mathrm{CH}_{2} \mathrm{Cl}_{2}, 16.6^{b}$ & $10.8 \pm 1.7$ & $0.36 \pm 0.06$ \\
\hline 3 & $\mathrm{~N}_{2}$ & 1,3-DCP, $5.7^{b, c}$ & $1.48 \pm 0.01$ & $1.63 \pm 0.01$ \\
\hline 3 & $\mathrm{~N}_{2}$ & $1,3-\mathrm{DCP}, 5.7^{b, d}$ & $1.24 \pm 0.01$ & $1.36 \pm 0.01$ \\
\hline
\end{tabular}

${ }^{a}$ Initial concentration of mercury was $0.5-1.0 \mathrm{ppm}$. The reaction flask was coated with halocarbon wax unless stated otherwise. ${ }^{b}$ In the presence of 835 ppm benzene. ${ }^{c}$ Noncoated flask. ${ }^{d}$ DMDCS coating.

Further evidence of $\mathrm{HO}$ involvement was obtained in additional experiments with continuous MS sampling, which revealed that the relative rate plots of decay of $\mathrm{Hg}^{0}$ versus that of dichloromethane and 1,3-DCP were noticeably curved (Figure 4b). Similar curved plots have already been reported in relative rate studies on the reaction of atomic chlorine with $\mathrm{CS}_{2}{ }^{28}$ and benzene $\frac{30-32}{2}$ in air, using methane, chloromethane, or chlorodifluoromethane as a reference. Such behavior was attributed to involvement of $\mathrm{HO}$ radicals. ${ }^{28}$ Since benzene and $\mathrm{CS}_{2}$ react with $\mathrm{HO}$ radicals more rapidly than methane, only their decay rates were enhanced. As the irradiation proceeded, accumulating oxidation products competed for $\mathrm{HO}$ radicals, decreasing the apparent depletion rate of benzene and $\mathrm{CS}_{2}$. Indeed, when we added an increasing amount of benzene, which effectively traps $\mathrm{HO}\left(1.19 \times 10^{-12} \mathrm{~cm}^{3} \mathrm{molecule}^{-1} \mathrm{~s}^{-1} 33\right)$ but does not react with chlorine $\left(<5.0 \times 10^{-16} \mathrm{~cm}^{3}\right.$ molecule $\left.{ }^{-1} \mathrm{~s}^{-1}{ }^{30}\right)$, the concentration-time profiles of mercury and reference $(1,3$ DCP and $\mathrm{CH}_{2} \mathrm{Cl}_{2}$ ) changed as shown in Figure 4a, resulting in less bent relative rate plots (Figure 4b, plots 2 and 4 ). Reaction of $\mathrm{CH}_{2} \mathrm{Cl}_{2}$ with chlorine atoms appears to be too slow, therefore, only 1,3-DCP was used in subsequent experiments with direct sampling. At $\left[\mathrm{C}_{6} \mathrm{H}_{6}\right]>800 \mathrm{ppm}$ and $[1,3-\mathrm{DCP}]<3.5 \mathrm{ppm}$, the relative rate plots were straight and the rate constant did not depend on concentration of the reference (Table 4), providing evidence that contribution of secondary reactions due to $\mathrm{HO}$ or any other species was eliminated. 


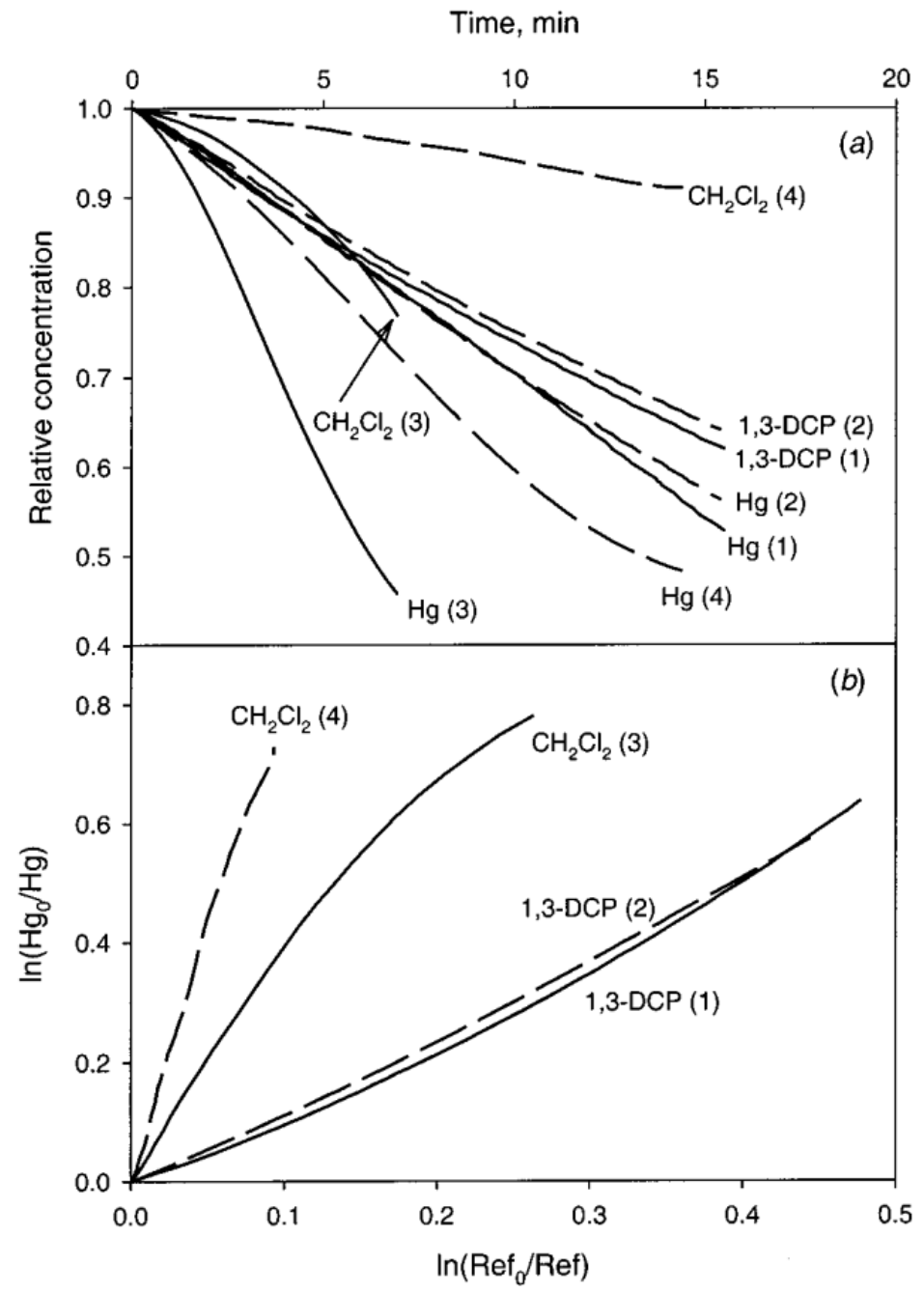

Figure 4. Time evolution of relative concentrations of mercury and reference at $298 \mathrm{~K}$ upon photolysis in nitrogen (a) and corresponding relative rate plots (b): (1) $\mathrm{Hg} 1 \mathrm{ppm}, 1,3-\mathrm{DCP} 5.7 \mathrm{ppm}$; (2) $\mathrm{Hg} 1 \mathrm{ppm}$, 1,3-DCP 5.7 ppm, $\mathrm{C}_{6} \mathrm{H}_{6} 835$ ppm; (3) $\mathrm{Hg} 1 \mathrm{ppm}, \mathrm{CH}_{2} \mathrm{Cl}_{2} 8.3 \mathrm{ppm}$; (4) $\mathrm{Hg} 1 \mathrm{ppm}, \mathrm{CH}_{2} \mathrm{Cl}_{2} 16.6 \mathrm{ppm}, \mathrm{C}_{6} \mathrm{H}_{6} 835 \mathrm{ppm}$.

The effect of $\mathrm{HO}$ on the relative rate plots is a complex function of many variables, which include (i) the rate constants of the reactions of halogen atoms $(\mathrm{X})$ and $\mathrm{HO}$ radicals with mercury $\left(k_{\mathrm{X}+\mathrm{Hg}}, k_{\mathrm{HO}+\mathrm{Hg}}\right)$, the reference compound $\left(k_{\mathrm{X}+\mathrm{Ref}}, k_{\mathrm{HO}+\mathrm{Ref}}\right)$, and oxidation products; (ii) the rates with which the source and scavenger of $\mathrm{HO}$ radicals (hydroperoxide and aldehyde) accumulate as the reaction proceeds. Depending on the mutual ratios of these rate constants and rates, the relative rate plots may be linear or show different degrees of curvature, either upward or downward. Knowledge of an accurate rate constant value for the reaction between mercury and $\mathrm{HO}$ radical, $k_{\mathrm{Hg}+\mathrm{HO}}$, is crucial in assessing the contribution of $\mathrm{HO}$ and explaining the curvatures we observed. We performed a modeling study (Acuchem) on the chlorine-initiated oxidation of ethane and mercury in air diluent using two values of $k_{\mathrm{Hg}+\mathrm{HO}}$ that have recently been reported. ${ }^{11,12}$ When the lower value $8.7 \times 10^{-14} \mathrm{~cm}^{3} \mathrm{molecule}^{-1} \mathrm{~s}^{-1}(\text { at } 298 \mathrm{~K})^{11}$ was used in a model calculation, no effect of $\mathrm{HO}$ on the relative rate plots was observed. As Figure $5 \mathrm{displays,} \mathrm{neither} \mathrm{Hg}$ nor ethane depletion rates were influenced by $\mathrm{HO}$ radical because the ratios $k_{\mathrm{Cl}} / k_{\mathrm{HO}}$ for these species were very high (Table 3). On the contrary, employing the high value of $k_{\mathrm{Hg}+\mathrm{HO}}=1.6 \times 10^{-11} \mathrm{~cm}^{3}$ molecule $^{-1} \mathrm{~s}^{-1}$ (at $343 \mathrm{~K}$ ), ${ }^{12}$ produced plots that were significantly curved upward (Figure 5). This was in contradiction to our experiments, where the relative rate plots were reasonably straight. We varied the rate constant $k_{\mathrm{Hg}+\mathrm{HO}}$ between the upper and lower literature values until our experimental relative rate constant $k_{\mathrm{Hg}+\mathrm{Cl}} / k_{\text {ethane+Cl}}$ was reproduced at $k_{\mathrm{Hg}+\mathrm{HO}}=3 \times 10^{-12} \mathrm{~cm}^{3} \mathrm{molecule}^{-1} \mathrm{~s}^{-1}$. The calculated relative rate plots were straight except for a slight bend upward at the very beginning of the curve, 
resembling the experimental plots at high concentration of ethane in the presence of molecular oxygen. Due to the discrepancy in the existing literature experimental kinetic data on the reaction of HO radical with elemental mercury, additional accurate experimental evaluation of $k_{\mathrm{Hg}+\mathrm{HO}}$ is desirab

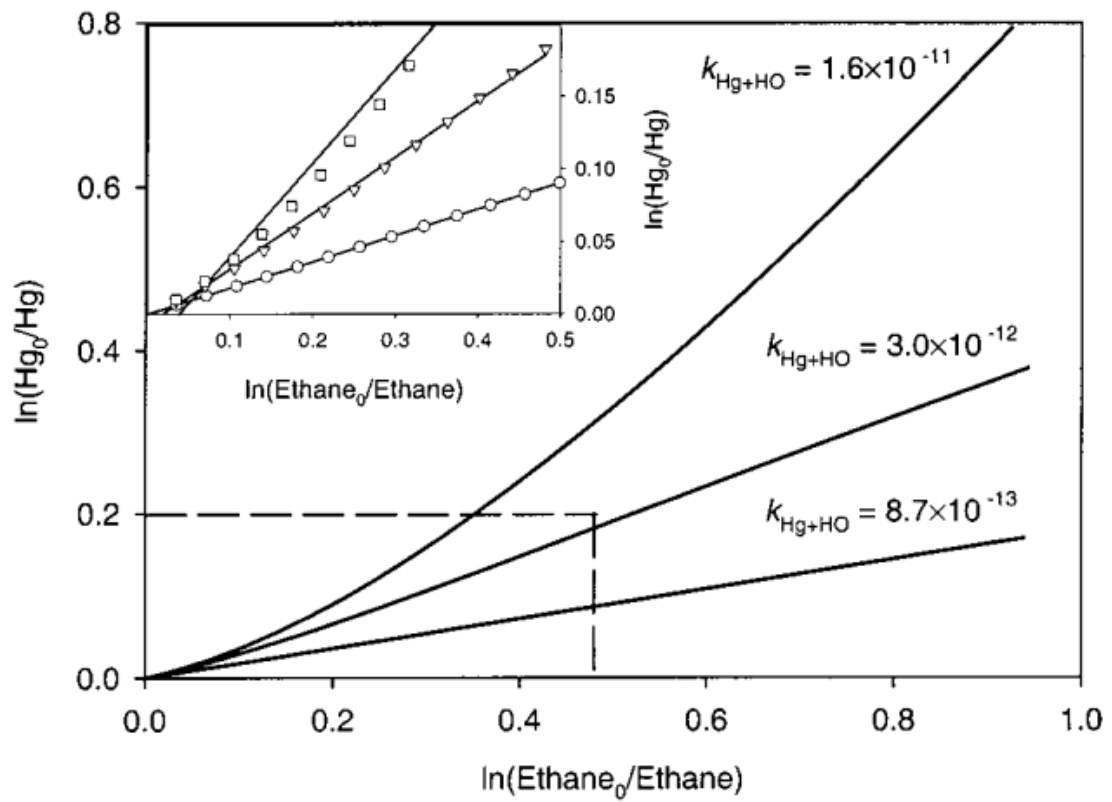

Figure 5. Relative rate plots of mercury versus ethane based on concentrations calculated using the kinetic model at different values of $k_{\mathrm{Hg}+\mathrm{HO}}\left(\mathrm{cm}^{3}\right.$ molecule $\left.\mathrm{e}^{-1} \mathrm{~s}^{-1}\right)$. Initial concentrations of mercury and ethane were 1 and $4 \mathrm{ppm}$, respectively, in an air diluent at $298 \mathrm{~K}$. Inset shows the beginning part of the relative rate plots. The lines representing best linear fits to the data points are drawn to show the bending more clearly.

Table 4 shows that when generation of HO radicals was minimized by either using the small concentration of reference, adding of $\mathrm{HO}$ scavenger, or carrying out the reaction in nitrogen, the relative rate constant did not depend on reaction conditions. For instance, in the presence of benzene the experimental rate constant, $k_{\mathrm{Hg}+\mathrm{Cl}}=(1.0 \pm 0.2) \times$ $10^{-11} \mathrm{~cm}^{3}$ molecule ${ }^{-1} \mathrm{~s}^{-1}$ obtained using 1,3-DCP did not essentially depend on the reference concentration and within experimental uncertainty was equal to the rate constant obtained using a small concentration of ethane in nitrogen. This value is very close to the rate constant $1.5 \times 10^{-11} \mathrm{~cm}^{3}$ molecule $\mathrm{e}^{-1} \mathrm{~s}^{-1}$ derived by Horne ${ }^{19}$ from the experimental data obtained in a mixture of 10 Torr $\mathrm{CF}_{3} \mathrm{Cl}$ and 710 Torr Ar.

As Table 4 shows, either using a flask with less efficient DMDCS coating or a noncoated flask did not significantly affect the rate constant of the reaction of mercury with atomic chlorine. Hence, the adsorption did not bias the reaction kinetics, and surface catalysis was negligible, as the reactions of atomic halogens proceed rapidly. This was in contrast to our findings for the reaction of mercury with molecular halogens, where catalysis occurring on the walls was significant.

Reaction $\mathrm{Hg}^{0}+\mathrm{Br}$. Reaction of bromine atoms with mercury was studied using 1-butene as a reference. Figure 6 shows noticeable bending of the relative rate plot obtained with only $\mathrm{Hg}^{0}, 1$-butene, and $\mathrm{CH}_{2} \mathrm{Br}_{2}$ in air. Experiments in the presence of small amounts of cyclohexane and $n$-nonane revealed that these alkanes were being depleted upon photolysis and additional products were formed in an air diluent. Since neither cyclohexane nor $n$-nonane react with atomic bromine $\left(1.01 \times 10^{-17} \mathrm{~cm}^{3}\right.$ molecule $\left.{ }^{-1} \mathrm{~s}^{-134}\right)$ or are photolyzed, depletion of these alkanes indicated involvement of some active species that were able to effectively attack an alkane $\mathrm{C}-\mathrm{H}$ bond. The slope of a relative rate plot, $k_{\text {cyclohexane }} / k_{n \text {-nonane }}=0.54 \pm 0.10$ within experimental uncertainty was close to the ratio 0.643 calculated using literature values ${ }^{35,36}$ of the rate constants for the reaction of these alkanes with the HO radical. As in the experiment with atomic chlorine, one can expect the contribution due to HO to minimize if the reaction is studied in the presence of an HO scavenger or in nitrogen diluent. Indeed, addition of high concentrations of cyclohexane, which effectively traps HO radicals $\left(7.20 \times 10^{-12} \mathrm{~cm}^{3}\right.$ molecule $\left.\mathrm{s}^{-1} \mathrm{~s}^{35}\right)$, to a mixture of reactants in air, straightened the plots (Figure 6). 
At the same time, the relative rate constant dramatically increased when nitrogen was used as a diluent (Table 5). Apparently, the latter effect was due to backward decomposition of $\mathrm{C}_{4} \mathrm{H}_{8} \mathrm{Br}$ (13) competing with its reaction with molecular oxygen (14)

$$
\begin{gathered}
\mathrm{Br}+1-\mathrm{C}_{4} \mathrm{H}_{8} \rightleftharpoons \mathrm{C}_{4} \mathrm{H}_{8} \mathrm{Br} \\
\mathrm{C}_{4} \mathrm{H}_{8} \mathrm{Br}+\mathrm{O}_{2} \rightarrow \text { products }
\end{gathered}
$$

Bromoalkyl radicals of this type are known to be only 6 to $8 \mathrm{kcal} \mathrm{mol}^{-1}$ more stable than the reactants. In air, $\mathrm{C}_{4} \mathrm{H}_{8} \mathrm{Br}$ is removed via reaction with molecular oxygen, while in nitrogen it may reversibly decompose, lowering the apparent absolute depletion rate of 1-butene. ${ }^{37}$ This led to an observed increase of the relative rate constant $k_{\mathrm{Hg}} / k_{1-b u t e n e}$, since the absolute rate of mercury depletion was not affected. Thus, the reaction must be studied in the presence of molecular oxygen in high enough concentration to suppress backward reaction 13.

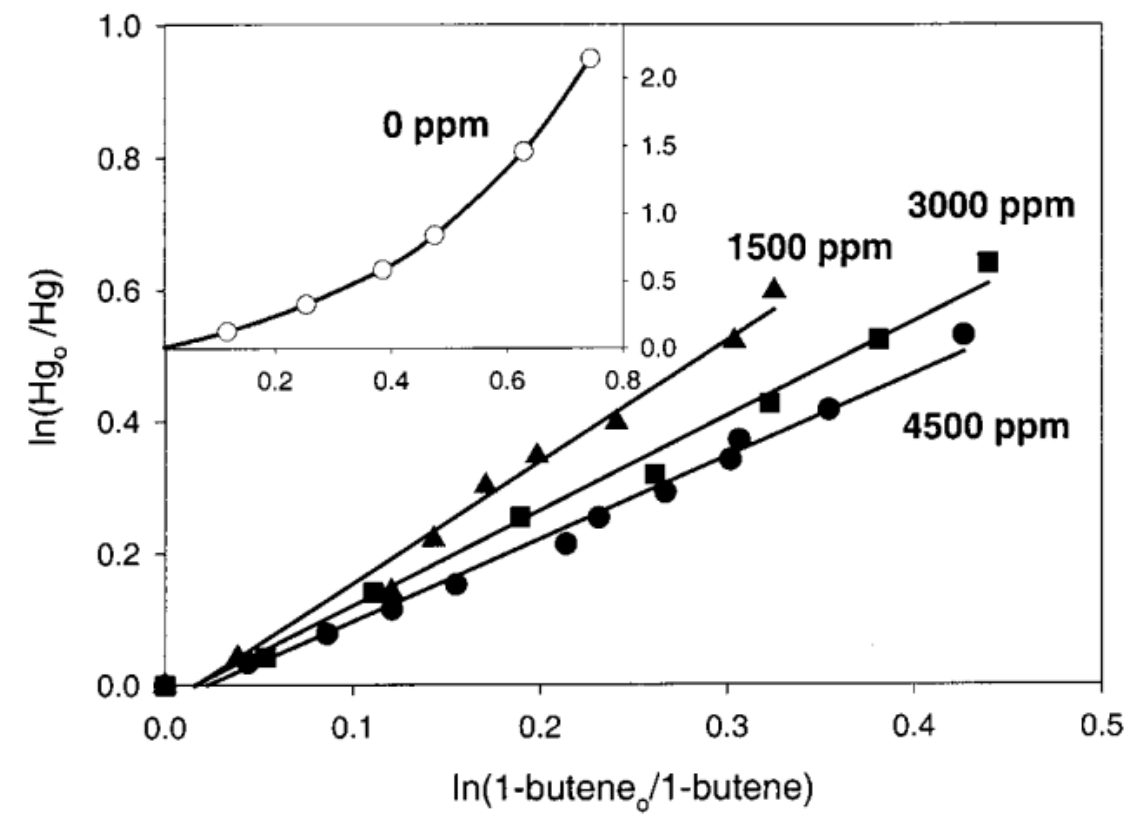

Figure 6. Relative rate data for reaction $\mathrm{Hg}^{0}+\mathrm{Br}$ obtained using 1-butene as a reference and $\mathrm{CH}_{2} \mathrm{Br}_{2}$ as a bromine atom source. Kinetic runs were performed at $298 \mathrm{~K}$ in air in the presence of different concentrations of the $\mathrm{HO}$ radicals scavenger-cyclohexane. Inset shows curvature of the relative rate plot when the scavenger was not added. 


\section{TABLE 5: Rate Constants for the Reaction of Mercury with Bromine Obtained Using the Syringe Sampling Method at $298 \mathrm{~K}^{a}$}

\begin{tabular}{|c|c|c|c|c|c|}
\hline$V_{\mathrm{fl}}, \mathrm{L}$ & $\begin{array}{c}\text { bath } \\
\text { gas }\end{array}$ & $\begin{array}{l}\text { 1-butene, } \\
\text { ppm }\end{array}$ & $\begin{array}{c}\text { cyclohexane, } \\
\text { ppm }\end{array}$ & $k_{\mathrm{Hg}} / k_{\mathrm{Ref}}$ & $k_{\mathrm{Hg}+\mathrm{Br}} \times 10^{12}$ \\
\hline 3 & air & 4 & 0 & \multicolumn{2}{|c|}{ bending } \\
\hline 3 & air & 4 & 0 & \multicolumn{2}{|c|}{ bending } \\
\hline 3 & $\mathrm{~N}_{2}$ & 4 & 0 & \multicolumn{2}{|c|}{ bending } \\
\hline 3 & air & 4 & 1000 & $1.66 \pm 0.17$ & $5.66 \pm 0.58$ \\
\hline 3 & $\mathrm{~N}_{2}$ & 4 & 1000 & $4.95 \pm 0.73$ & $16.83 \pm 2.48$ \\
\hline 2 & air & 6 & 1500 & $1.87 \pm 0.17$ & $6.37 \pm 0.58$ \\
\hline 2 & air & 6 & 3000 & $1.45 \pm 0.11$ & $4.93 \pm 0.37$ \\
\hline 2 & air & 2 & 3000 & $0.94 \pm 0.06$ & $3.20 \pm 0.20$ \\
\hline 2 & air & 6 & 4500 & $1.15 \pm 0.08$ & $3.90 \pm 0.27$ \\
\hline
\end{tabular}

${ }^{a}$ Initial concentration of mercury was $0.5-1.0 \mathrm{ppm}$; 1-butene was used as a reference.

If reactions 13 and 14 are the principal pathways of formation and depletion of the $\mathrm{C}_{4} \mathrm{H}_{8} \mathrm{Br}$ radical, at steady-state we will have

$$
\begin{aligned}
& \mathrm{d}\left[\mathrm{C}_{4} \mathrm{H}_{8}\right] / \mathrm{d} t= \\
& \left\{k_{13} k_{14}\left[\mathrm{O}_{2}\right] /\left(k_{-13}+k_{14}\left[\mathrm{O}_{2}\right]\right)\right\}\left[1-\mathrm{C}_{4} \mathrm{H}_{8}\right][\mathrm{Br}]= \\
& k_{13}{ }^{\prime}\left[1-\mathrm{C}_{4} \mathrm{H}_{8}\right][\mathrm{Br}]
\end{aligned}
$$

Since there have been no experimental measurements of the rate constant $k_{-13}$ for backward decomposition of $\mathrm{C}_{4} \mathrm{H}_{8} \mathrm{Br}$, we evaluated it using the experimental value of $k_{13}$ and equilibrium constant $K_{\mathrm{eq}}=4.5 \times 10^{-19} \mathrm{~cm}^{3}$ molecule ${ }^{-1}$ defined as

$$
k_{-13}=k_{13} / K_{\mathrm{eq}}=k_{13} / \exp \left(-\Delta_{\mathrm{r}} G^{298} / R T\right)
$$

The free energy of reaction $13, \Delta_{\mathrm{r}} G^{298}$, was evaluated to be $-1.4 \mathrm{kcal} \mathrm{mol}^{-1}$ using $\Delta_{\mathrm{r}} H^{298}=-8.8 \mathrm{kcal} \mathrm{mol}^{-1}$ and $\Delta_{\mathrm{r}} S^{298}=$ $-24.8 \mathrm{cal} \mathrm{mol}^{-1} \mathrm{~K}^{-1}$. The reaction enthalpy was assumed to be the same as for reaction of atomic bromine with transbutene. ${ }^{38,39}$ The reaction entropy was calculated by standard thermochemical analysis of the structures of reaction 13 reactants and products optimized at the HF/6-31G* level. Substituting these data into eq 16 gives $k_{-13}=7.5 \times 10^{6} \mathrm{~s}^{-1}$. One can see that the ratio $k_{14}\left[\mathrm{O}_{2}\right] /\left(k_{-13}+k_{14}\left[\mathrm{O}_{2}\right]\right)$ is very small when the experiment is carried out in nitrogen with only trace amounts of molecular oxygen present, $\left[\mathrm{O}_{2}\right]=(1-10) \times 10^{13}$ molecule $\mathrm{cm}^{-3}$, and the effective rate constant $k_{13}{ }^{6}$ is lower than $k_{13}$, leading to an apparent increase of $k_{\mathrm{Hg}+\mathrm{Br}} / k_{13}{ }^{6}$. The contribution of backward reaction 13 can be neglected only at $\left[\mathrm{O}_{2}\right] \geq 5 \times 10^{18}$ molecule $\mathrm{cm}^{-3}$, therefore, we studied the reaction between mercury and bromine atoms in air diluent. As the $\mathrm{HO}$ radical is very reactive toward 1-butene (Table 3), the addition of very high concentrations (3000-4500 ppm) of cyclohexane, the $\mathrm{HO}$ radical scavenger, was necessary. A set of experiments was performed at different concentrations of 1-butene and cyclohexane to determine conditions when $k_{\mathrm{Hg}+\mathrm{Br}}$ can be measured accurately. The strategy was to use lower concentration of 1-butene to minimize HO production while keeping [1-butene] above $2 \mathrm{ppm}$ so it could be measured accurately. We also tried to avoid using very high concentrations of cyclohexane because it led to an enhanced adsorption of all reactants, probably due to the formation of a liquid film of cyclohexane on the wall. The optimal concentrations of the reference and scavenger were found to be 2 and $3000 \mathrm{ppm}$, respectively. The rate constant obtained at these conditions, $k_{\mathrm{Hg}+\mathrm{Br}}=(3.2 \pm 0.3) \times 10^{-}$ ${ }^{12} \mathrm{~cm}^{3}$ molecule $\mathrm{e}^{-1} \mathrm{~s}^{-1}$, did not change when the concentration of 1-butene was decreased or the concentrations of cyclohexane were increased, providing evidence that the contribution from $\mathrm{HO}$ was eliminated.

3.3.2. Product Studies. None of the experiments showed the presence of gaseous mercury oxidation products with either syringe or direct MS sampling of gas mixtures. A possible explanation is the low vapor pressure of the products at room temperature and the significantly lower sensitivity of the MS instrument to oxidized mercury than to $\mathrm{Hg}^{0}$. As 
described in the Experimental Section, three different methods were employed to identify the reaction products. DMDCS coating, which is stable against organic solvents, was used to prevent undesirable wall processes.

In the first method, after the reaction was completed the flask was heated to $353 \mathrm{~K}$, volatile and possible particulate products were collected by passing the gas mixture through a small tube cooled to liquid nitrogen temperature, and the tube was sealed at both ends. Half of the tube was placed in the direct probe of the MS instrument and heated stepwise to $700 \mathrm{~K}$. Mass spectra corresponding to $\mathrm{HgCl}_{2}$ and $\mathrm{HgBr}_{2}$ (Figure 7) were observed in the temperature range of 300-500 $\mathrm{K}$ for the products of reaction of $\mathrm{Hg}^{0}$ with atomic chlorine and bromine, respectively. No additional signal was observed when the temperature was elevated to $700 \mathrm{~K}$. Thus, the collected products did not contain $\mathrm{Hg}_{2} \mathrm{Br}_{2}$ and $\mathrm{Hg}_{2} \mathrm{Cl}_{2}$, which were expected to decompose in the probe to $\mathrm{HgCl}$ and $\mathrm{HgBr}$ at high temperatures, producing corresponding mass spectra. This observation is in an apparent contradiction with the results of the early study by Horne et al. ${ }^{19}$ who found $\mathrm{Hg}_{2} \mathrm{Cl}_{2}$ as the dominant reaction product. Their method employed the flash photolysis technique where atomic chlorine generated by the light flash (reaction 1) was rapidly consumed in reaction 2 with mercury that was present in very high concentration, up to $300 \mathrm{ppm}$. Therefore, the only possible pathway for $\mathrm{HgCl}$ was its mutual recombination (reaction 3). In our experiments we employed the relative rate technique and atomic halogens were generated continuously in relatively high concentrations, $10^{7}-10^{8}$ atom $\mathrm{cm}^{-3}$, leading to reaction 17 as the dominant pathway for $\mathrm{HgX}$ :

$$
\mathrm{HgX}+\mathrm{X} \rightarrow \mathrm{HgX}_{2}
$$
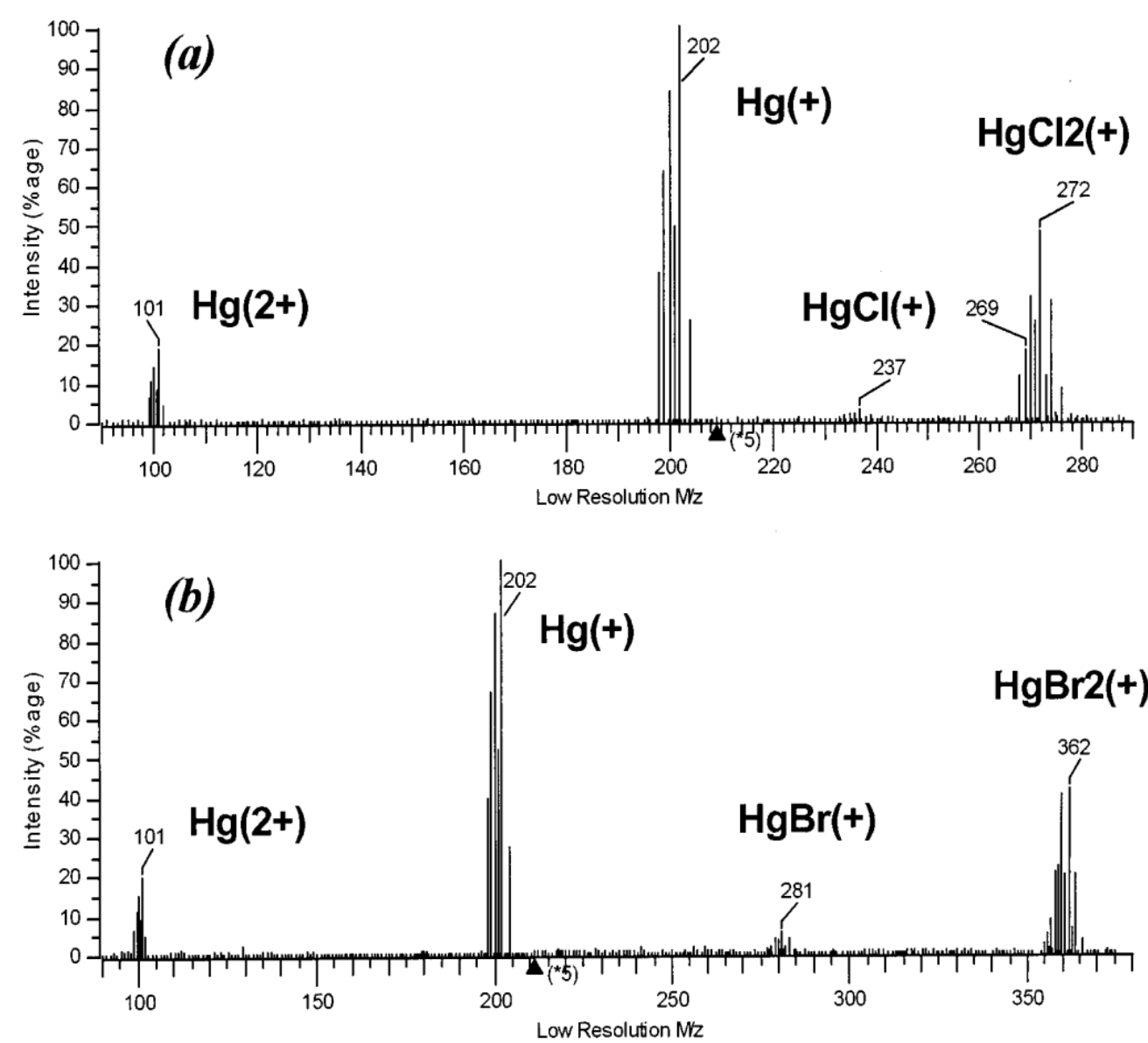

Figure 7. Mass spectra of volatile products formed in the reactions of $\mathrm{Hg}^{0}$ : (a) $\mathrm{HgCl}_{2}$, (b) $\mathrm{HgBr}_{2}$.

In several experiments the reaction flask was evacuated through a 0.5 or 1 micron Teflon filter to a residual pressure of 0.5 Torr. The filter was treated with an $\mathrm{HNO}_{3} / \mathrm{H}_{2} \mathrm{O}_{2}$ mixture. ICP-MS analysis recovered $0.0 \%$ to $0.5 \%$ of mercury relative to the amount of $\mathrm{Hg}^{0}$ loaded in the flask, showing that aerosols did not make any significant contribution to reaction products. In the second method, the reaction products were collected in a cooled coiled Pyrex trap, washed 
with toluene, derivatized, and analyzed using a GC-MS (Figure 8). This analysis recovered only $6 \%$ to $15 \%$ of the mercury that was loaded as $\mathrm{Hg}^{0}$ into the reaction flask. Additional testing with the $\mathrm{HgCl}_{2}$ standard showed that employing the heating/evacuation procedure could not recover all $\mathrm{HgCl}_{2}$, which apparently stuck to the walls of the reaction flask. Therefore, the collection procedure was modified: the inside of the flask was washed several times with small amounts of hot toluene, then the toluene samples were combined and derivatized. This resulted in $88.5 \%$ and $82.6 \%$ yields of $\mathrm{Hg}^{2+}$ in the reaction with atomic chlorine and bromine, respectively. As Table 1 displays, the adsorption of $\mathrm{Hg}^{0}$ on DMDCS coating was about $12 \%$. Elemental mercury is not accounted for by derivatization analysis, therefore, the latter value practically recovers the difference of $12-18 \%$ from the quantitative yield. Since contribution of aerosols to the products was shown to be unimportant under our experimental conditions, the amount of $\mathrm{Hg}_{2} \mathrm{X}_{2}$ and $\mathrm{HgO}$ in particulate form on the walls seems to be negligible.

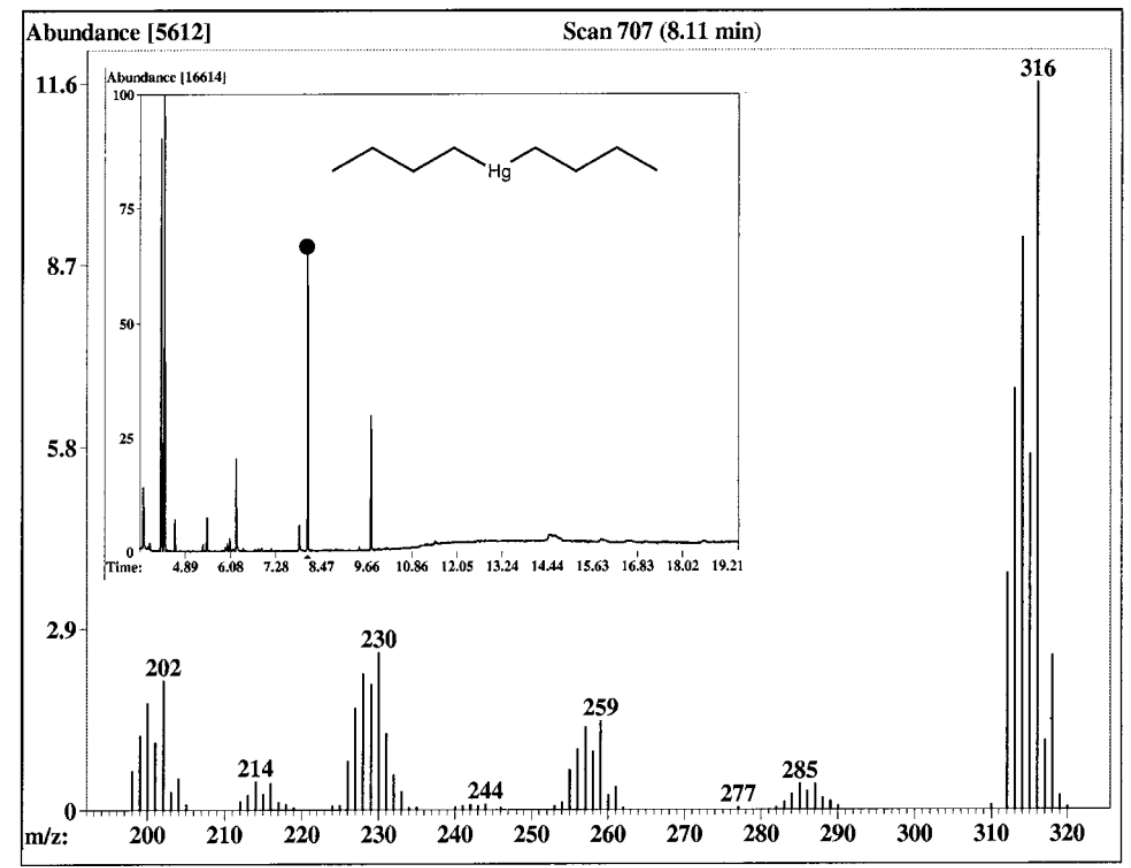

Figure 8. Mass spectrum of the chromatographic peak eluted at 8.1 min corresponding to derivatized mercury (di- $n$-butylmercury). The gas chromatogram (total ionogram) is shown on the inset.

\section{Atmospheric Implications}

To evaluate the boundary layer importance of halogen reactions of mercury in light of this kinetic study, we summarized in Table 6 the lifetime of mercury upon its reaction with selected atmospherically important oxidants, capable of destroying mercury in the Arctic. Similar to the reaction of $\mathrm{O}_{3}$ with $\mathrm{Hg}^{0,40,41}$ the reactions of $\mathrm{Cl}_{2}$ and $\mathrm{Br}_{2}$ with $\mathrm{Hg}^{0}$ are far too slow to be important atmospheric "sinks" for mercury. At hydroxyl radical concentrations of $10^{5}$ or even $10^{6}$ molecule $\mathrm{cm}^{-3}$, to account for potential high concentration of $\mathrm{HO}$ within the boundary layer, observed mercury depletion could not be reproduced. Despite the fast rate coefficient of $\mathrm{Cl}$ atom initiated reaction of mercury measured $\left(k_{\mathrm{Hg}+\mathrm{Cl}}=(1.0 \pm 0.4) \times 10^{-11} \mathrm{~cm}^{3}\right.$ molecule $\left.^{-1} \mathrm{~s}^{-1}\right)$, the inferred concentration of chlorine atoms $\mathrm{s}^{6,7}$ is far too low to play a significant role in the destruction of mercury. The $\mathrm{Br}$ atom reaction, however, is sufficiently fast, and $\mathrm{Br}$ is present in high enough concentrations to exclusively destroy mercury completely within a couple of days, as observed in the Arctic. Though this evaluation was performed using the rate constants at $298 \mathrm{~K}$, we expect it to be valid at temperatures as low as $230 \mathrm{~K}$ typical of the Arctic troposphere in the springtime. A simple atomic recombination is known to reveal a weak negative or no temperature dependence, therefore, the rate constant $k_{\mathrm{Hg}+\mathrm{X}}$ is expected to be the same or even to increase slightly at lower temperatures. The above conclusion is well supported by Horne et al. ${ }^{19}$ who observed independence of the rate constant $k_{\mathrm{Hg}+\mathrm{Cl}}$ at temperatures between 383 and $443 \mathrm{~K}$. 
TABLE 6: Lifetime of $\mathrm{Hg}^{0}$ upon Reaction with Selected Atmospheric Oxidants at $298 \mathrm{~K}$

\begin{tabular}{|c|c|c|c|c|}
\hline reaction & rate constant, $\mathrm{cm}^{3}$ molecule ${ }^{-1} \mathrm{~s}^{-1}$ & [oxidant], $\mathrm{cm}^{-3}$ & lifetime,${ }^{a}$ days & ref \\
\hline $\mathrm{Hg}^{0}+\mathrm{Cl}_{2} \rightarrow$ products & $(2.6 \pm 0.2) \times 10^{-18}$ & $2.5 \times 10^{10 b}$ & 178 & this study \\
\hline $\mathrm{Hg}^{0}+\mathrm{Br}_{2} \rightarrow$ products & $(0.9 \pm 0.2) \times 10^{-16}$ & $2.5 \times 10^{10 b}$ & 5 & this study \\
\hline $\mathrm{Hg}^{0}+\mathrm{Cl} \rightarrow$ products & $(1.0 \pm 0.4) \times 10^{-11}$ & $1 \times 10^{4}$ & 115 & this study \\
\hline \multirow[t]{2}{*}{$\mathrm{Hg}^{0}+\mathrm{Br} \rightarrow$ products } & $(3.2 \pm 0.4) \times 10^{-12}$ & $1 \times 10^{7}$ & 0.40 & this study \\
\hline & & $1 \times 10^{8}$ & 0.04 & \\
\hline $\mathrm{Hg}^{0}+\mathrm{O}_{3} \rightarrow$ products & $(3.0 \pm 2.0) \times 10^{-20}$ & $7.5 \times 10^{11}$ & 514 & Hall, $1995^{41}$ \\
\hline \multirow[t]{4}{*}{$\mathrm{Hg}^{0}+\mathrm{HO} \rightarrow$ products } & $(8.7 \pm 2.8) \times 10^{-14}$ & $1 \times 10^{5}$ & 1330 & Sommar et al., $2001^{11}$ \\
\hline & & $1 \times 10^{6}$ & 133 & \\
\hline & $(1.6 \pm 0.2) \times 10^{-11 c}$ & $1 \times 10^{5}$ & 7.2 & Miller et al., $2001^{12}$ \\
\hline & & $1 \times 10^{6}$ & 0.7 & \\
\hline
\end{tabular}
wavelengths during the polar sunrise and should be considered upper limits. ${ }^{c}$ At $343 \mathrm{~K}$.

Formation of condensed products in the gas-phase reactions of halogens with mercury is consistent with the observation of the increase in concentrations of oxidized mercury in aerosols and snow surfaces in the Arctic. ${ }^{4}$ Of particular concern is the deposition of mercury derivatives, since the transformation products of halogen-initiated reactions of elemental mercury identified in our experiments are much more water soluble than $\mathrm{Hg}^{0}$. Their ecological impact at the onset of peak biological activities, over a large part of the Northern Hemisphere ought to be carefully considered.

\section{Conclusion}

An extensive kinetic and product study of the reactions of gaseous $\mathrm{Hg}^{0}$ with $\mathrm{Cl}_{2}, \mathrm{Br} 2, \mathrm{Cl}$, and $\mathrm{Br}$ was performed at near atmospheric conditions using different experimental techniques. The kinetic data we obtained provide evidence that the reactions of $\mathrm{Hg}^{0}$ with molecular halogens are too slow to be important in atmospheric mercury transformation. Reactions of mercury with atomic halogens are considerably faster; however, in light of the observed or inferred concentrations of atomic chlorine and bromine, we believe that $\mathrm{Br}$ is the only likely candidate to explain the rapid depletions of mercury in the Arctic. Particular attention is to be placed on the identified products, $\mathrm{HgCl}_{2}$ and $\mathrm{HgBr}_{2}$, formed as the result of halogen-initiated reactions of elemental mercury, as they are more soluble than elemental mercury and, hence, may be subject to bioaccumulation.

\section{Author Information Authors}

Parisa A. Ariya - Departments of Chemistry and Atmospheric and Oceanic Sciences, McGill University, 801 Sherbrooke St. W., Montreal, PQ, Canada, H3A 2 K6

Alexei Khalizov - Departments of Chemistry and Atmospheric and Oceanic Sciences, McGill University, 801 Sherbrooke St. W., Montreal, PQ, Canada, H3A 2 K6

Alexios Gidas - Departments of Chemistry and Atmospheric and Oceanic Sciences, McGill University, 801 Sherbrooke St. W., Montreal, PQ, Canada, H3A 2 K6

\section{Acknowledgment}

We cordially thank the Natural Science and Engineering Research Council of Canada (NSERC), the Fond pour la Formation de Chercheurs et l'Aide a la Recherche (FCAR), the Canadian Foundation for Innovation (CFI), the COMERN project, the NATO/NSERC postdoctoral program, and Environment Canada for financial support. We also thank Mr. Dimitris Moraitis for his assistance in performing some of the experimental work.

\section{References and Notes}

(1) Schroeder, W. H.; Anlauf, K. G.; Barrie, L. A.; Lu, J. Y.; Steffen, A.; Schneeberger, D. R.; Berg, T. Nature 1998, $394,331-332$. (2) Lindberg, S. E.; Brooks, S.; Lin, C. J.; Scott, K. J.; Landis, M. S.; Stevens, R. K.; Goodsite, M.; Richter, A. EnViron. Sci. Technol. 2002, 36, 1245-1256.

(3) Poissant, L. 2001, personal communication. 
https://pubs.acs.org/doi/abs/10.1021/jp020719o

(4) Lu, J. Y.; Schroeder, W. H.; Barrie, L. A.; Steffen, A.; Welch, H. E.; Martin, K.; Lockhart, L.; Hunt, R. V.; Boila, G.; Richter, A. Geophys. Res. Lett. 2001, 28, 3219-3222.

(5) Barrie, L. A.; Bottenheim, J. W.; Schnell, R. C.; Crutzen, P. J.; Rasmussen, R. A. Nature 1988, 334, 138-141.

(6) Jobson, B. T.; Niki, H.; Yokouchi, Y.; Bottenheim, J.; Hopper, F.; Leaitch, R. J. Geophys. Res., [Atmos.] 1994, 99, 23355-23368.

(7) Ariya, P. A.; Jobson, B. T.; Sander, R.; Niki, H.; Harris, G. W.; Hopper, J. F.; Anlauf, K. G. J. Geophys. Res. 1998, 103, $13169-13180$.

(8) Ariya, P. A.; Niki, H.; Harris, G. W.; Anlauf, K. G.; Worthy, D. E. J. Atmos. EnViron. 1999, 33, 931-938.

(9) Yarwood, G.; Niki, H. A critical reView of aVailable information on transformation pathways for mercury species in the atmospheric enVironment; Centre for Atmospheric Chemistry and York University: Toronto, 1990.

(10) Stroemberg, D. Some mercury compounds studied by relativistic quantum chemical methods. Ph.D. Thesis, Goteborg University and Chelmers University of Technology, 1990.

(11) Sommar, J.; Gardfeldt, K.; Stromberg, D.; Feng, X. Atmos. EnViron. 2001, 35, 3049-3054. (12) Miller, G. C.; Quashnick, J.; Hebert, V. Abstr. Pap.-Am. Chem. Soc. 2001, 221st, AGRO-016.

(13) Tokos, J. J. S.; Hall, B.; Calhoun, J. A.; Prestbo, E. M. Atmos. EnViron. 1998, 32, 823-827. (14) Menke, R.; Wallis, G. Am. Ind. Hyg. Assoc. J. 1980, 41, 120- 124.

(15) Medhekar, A. K.; Rokni, M.; Trainor, D. W.; Jacob, J. H. Chem. Phys. Lett. 1979, 65, 600-604.

(16) Skare, I.; Johansson, R. Chemosphere 1992, 24, 1633-1644.

(17) Schroeder, W. H.; Yarwood, G.; Niki, H. Water, Air Soil Pollut. 1991, 56, 653-666.

(18) Seigneur, C.; Wrobel, J.; Constantinou, E. EnViron. Sci. Technol. 1994, 28, 1589-1597. (19) Horne, D. G.; Gosavi, R.; Strausz, O. P. J. Chem. Phys. 1968, 48, 4758-4764.

(20) Khamaganov, V. G.; Hites, R. A. J. Phys. Chem. A 2001, 105, 815-822.

(21) Finlayson-Pitts, B. J.; Keoshian, C. J.; Buehler, B.; Ezell, A. A. Int. J. Chem. Kinet. 1999, 31, 491-499.

(22) Bierbach, A.; Barnes, I.; Becker, K. H. Int. J. Chem. Kinet. 1996, 28, 565-577.

(23) The Book of Photon Tools; Oriel Inc.: Stratford, CT, 2000.

(24) Bulska, E.; Emteborg, H.; Baxter, D. C.; Frech, W.; Ellingsen, D.; Thomassen, Y. Analyst (London) 1992, 117, 657-63.

(25) Snell, J.; Qian, J.; Johansson, M.; Smit, K. Analyst (Cambridge, U.K.) 1998, 123, 905-909. (26) Frisch, M. J.; Trucks, G. W.; Schlegel, H. B.; Scuseria, G. E.; Robb, M. A.; Cheeseman, J. R.; Zakrzewski, V. G.; Montgomery, J. A., Jr.; Stratmann, R. E.; Burant, J. C.; Dapprich, S.; Millam, J. M.; Daniels, A. D.; Kudin, K. N.; Strain, M. C.; Farkas, O.; Tomasi, J.; Barone, V.; Cossi, M.; Cammi, R.; Mennucci, B.; Pomelli, C.; Adamo, C.; Clifford, S.; Ochterski, J.; Petersson, G. A.; Ayala, P. Y.; Cui, Q.; Morokuma, K.; Malick, D. K.; Rabuck, A. D.; Raghavachari, K.; Foresman, J. B.; Cioslowski, J.; Ortiz, J. V.; Stefanov, B. B.; Liu, G.; Liashenko, A.; Piskorz, P.; Komaromi, I.; Gomperts, R.; Martin, R. L.; Fox, D. J.; Keith, T.; Al-Laham, M. A.; Peng, C. Y.; Nanayakkara, A.; Gonzalez, C.; Challacombe, M.; Gill, P. M. W.; Johnson, B. G.; Chen, W.; Wong, M. W.; Andres, J. L.; Head-Gordon, M.; Replogle, E. S.; Pople, J. A. Gaussian 98, revision A.7; Gaussian, Inc.: Pittsburgh, PA, 1998.

(27) Braun, W.; Herron, J. T.; Kahaner, D. K. Int. J. Chem. Kinet. 1988, 20, 51-62.

(28) Wallington, T. J.; Andino, J. M.; Potts, A. R.; Wine, P. H. Chem. Phys. Lett. 1991, 176, 103-108.

(29) DeMore, W. B.; Sander, S. P.; Golden, D. M.; Hampson, R. F.; Kurylo, M. J.; Howard, C. J.; Ravishankara, A. R.; Kolb, C. E.; Molina, M. J. Chemical kinetics and photochemical data for use in stratospheric modeling; Evaluation number 12, JPL Publication 97-4; Jet Propulsion Laboratory, California Institute of Technology: Pasadena, CA, 1997.

(30) Noziere, B.; Lesclaux, R.; Hurley, M. D.; Dearth, M. A.; Wallington, T. J. J. Phys. Chem. 1994, 98, 2864-2873.

(31) Ariya, P. A. Studies of Tropospheric Halogen Chemistry: Laboratory and Field Measurement. Ph.D. Thesis, York University, Toronto, 1996.

(32) Sokolov, O.; Hurley, M. D.; Wallington, T. J.; Kaiser, E. W.; Platz, J.; Nielsen, O. J.; Berho, F.; Rayez, M. T.; Lesclaux, R. J. Phys. Chem. A 1998, 102, 10671-10681.

(33) Semadeni, M.; Stocker, D. W.; Kerr, J. A. Int. J. Chem. Kinet. 1995, 27, 287-304.

(34) Ferguson, K. C.; Whittle, E. Trans. Faraday Soc. 1971, 67, 2618.

(35) Kramp, F.; Paulson, S. E. J. Phys. Chem. A 1998, 102, 2685- 2690.

(36) Cohen, N. Int. J. Chem. Kinet. 1991, 23, 397-417.

(37) Barnes, I.; Bastian, V.; Becker, K. H.; Overath, R.; Tong, Z. Int. J. Chem. Kinet. 1989, 21, 499-517.

(38) Bedjanian, Y.; Poulet, G.; Le Bras, G. J. Phys. Chem. A 1999, 103, 4026-4033.

(39) Bedjanian, Y.; Poulet, G.; Le Bras, G. J. Phys. Chem. A 1998, 102, 5867-5875.

(40) P'yankov, V. A. Zh. Obsch. Khim. (Russ. J. Gen. Chem.) 1949, 19, 224-229.

(41) Hall, B. Water, Air, Soil Pollut. 1995, 80, 301-315.

(42) Donahue, N. M.; Anderson, J. G.; Demerjian, K. L. J. Phys. Chem. A 1998, 102, 3121-3126.

(43) Donaghy, T.; Shanahan, I.; Hande, M.; Fitzpatrick, S. Int. J. Chem. Kinet. 1993, 25, 273-284.

(44) Villenave, E.; Orkin, V. L.; Huie, R. E.; Kurylo, M. J. J. Phys. Chem. A 1997, 101, 8513-8517.

(45) Ariya Hooshiyar, P. A.; Niki, H. Int. J. Chem. Kinet. 1995, 27, 1197-1206.

(46) Tyndall, G. S.; Orlando, J. J.; Wallington, T. J.; Dill, M.; Kaiser, E. W. Int. J. Chem. Kinet. 1997, 29, 43-55.

(47) Atkinson, R. Chem. ReV. 1986, 86, 69. 